\title{
Coupling SAR C-band and optical data for soil moisture and leaf area index retrieval over irrigated grasslands
}

\author{
Nicolas Baghdadi ${ }^{1}$, Mohamad El Hajj ${ }^{1}$, Mehrez Zribi ${ }^{2}$, Ibrahim Fayad ${ }^{1}$
}

${ }^{1}$ IRSTEA, UMR TETIS, 500 rue François Breton, 34093 Montpellier cedex 5, France

${ }^{2}$ CESBIO, 18 av. Edouard Belin, bpi 2801, 31401 Toulouse cedex 9, France

\begin{abstract}
The objective of this study was to develop an approach for estimating soil moisture and vegetation parameters in irrigated grasslands by coupling C-band polarimetric Synthetic Aperture Radar (SAR) and optical data. A huge dataset of satellite images acquired from RADARSAT-2 and LANDSAT-7/8, and in situ measurements were used to assess the relevance of several inversion configurations. A neural network (NN) inversion technique was used. The approach for this study was to use RADARSAT-2 and LANDSAT-7/8 images to investigate the potential for the combined use of new data from the new SAR sensor SENTINEL-1 and the new optical sensors LANDSAT-8 and SENTINEL-2. First, the impact of SAR polarization (mono-, dual- and full-polarizations configurations) and the Normalized Difference Vegetation Index (NDVI) calculated from optical data for the estimation error of soil moisture and vegetation parameters was studied. Next, the effect of some polarimetric parameters (Shannon entropy and Pauli components) on the inversion technique was also analyzed. Finally, configurations using in situ measurements of the fraction of absorbed photosynthetically active radiation (FAPAR) and the fraction of green vegetation cover (FCover) were also tested.
\end{abstract}

The results showed that $\mathrm{HH}$ polarization is the SAR polarization most relevant to soil moisture estimates. An RMSE for soil moisture estimates of approximately 6 vol.\% was obtained even for dense grassland cover. The use of in situ FAPAR and FCover only improved the estimate of the leaf area index (LAI) with an RMSE of approximately $0.37 \mathrm{~m}^{2} / \mathrm{m}^{2}$. The use of polarimetric parameters did not improve the estimate of soil moisture and vegetation parameters. Good results were obtained 
in : IEEE Journal of Selected Topics in Applied Earth Observations and Remote Sensing, $n^{\circ}$ 99, 2015. p.1-15

for the biomass (BIO) and vegetation water content (VWC) estimates for BIO and VWC values lower than 2 and $1.5 \mathrm{~kg} / \mathrm{m}^{2}$, respectively (RMSE is of $0.38 \mathrm{~kg} / \mathrm{m}^{2}$ for $\mathrm{BIO}$ and $0.32 \mathrm{~kg} / \mathrm{m}^{2}$ for VWC). In addition, a high under-estimate was observed for BIO and VWC higher than 2 and $1.5 \mathrm{~kg} / \mathrm{m}^{2}$, respectively (a bias of $-0.65 \mathrm{~kg} / \mathrm{m}^{2}$ on $\mathrm{BIO}$ estimates and $-0.49 \mathrm{~kg} / \mathrm{m}^{2}$ on $\mathrm{VWC}$ estimates). Finally, the estimation of vegetation height (VEH) was carried out with an RMSE of $13.45 \mathrm{~cm}$.

Index Terms - soil moisture, leaf area index, biomass, vegetation water content, canopy height, irrigated grassland, RADARSAT-2, LANDSAT.

\section{INTRODUCTION}

Agricultural areas consume approximately $70 \%$ of globally available water [1]. In the next 50 years, the world population will increase by approximately 65\% [2] which will require an increase in agricultural areas as well as water consumption. Recently, farmers tended to alter irrigation and agricultural practices to adapt to severe climatic conditions, such as drought. For example, during a drought, farmers increased the water consumption and used more fertilizer to maintain good productivity. Such a scenario could lead to a negative impact on soil productivity and the pollution of groundwater. Therefore, it is essential to develop a methodology for the monitoring vegetation conditions and to predict the impact of agricultural practices on yields as well as on the environment.

In irrigated grasslands, soil moisture and temperature are the two most influential factors that control the grass growth rate and consequently the yield [3]. Moreover, the leaf area index (LAI) of a grassland is a key factor that characterizes grassland growth, the growth stage and health [4]. In this context, monitoring the spatio-temporal behavior of soil moisture and LAI is important for supervising grassland areas. Remote sensing technology is a valuable tool for grassland monitoring because it can provide spatially continuous information on soil and vegetation conditions by means of frequent sampling. SAR (Synthetic Aperture Radar) data have shown great potential for soil moisture estimation of vegetated areas [5-15]. With 
NASA's new Soil Moisture Active Passive (SMAP) mission (launched January 31, 2015), a global scale soil moisture map is available with a spatial resolution of $10 \mathrm{~km} \times 10 \mathrm{~km}$ and a frequent revisit time (approximately 3 days) [16]. Moreover, some studies showed the potential of SAR data for the estimating crop parameters, such as height, biomass, and LAI [17-19]. On the other hand, optical remote sensing data has always been used to estimate crop parameters such as LAI, biomass, height, and water content [20-30]. However, it has always been difficult to provide information on soil and vegetation parameters at the plot scale with frequent resampling. Thus, the development of tools to supervise soil and vegetation conditions was required at a very high spatial resolution with frequent revisit.

Several studies have developed crop models that principally predict yields at daily time intervals and to define the optimum irrigation scheduling in order to improve the efficiency of water use. However, crop model outputs are not reliable due to the uncertainties in either the model equations, the input variables, or the model parameters [31]. To reduce such uncertainties, numerous studies used remote sensing observations such as the input of the crop models [32,33]. Two approaches were adopted to incorporate remote sensing data into crop models: forcing functions, and simulation steering $[34,35]$. Forcing functions are used to replace parameters simulated by the crop model with remote sensing observations, while simulation steering is used to re-parametrize the crop model by minimizing the difference between simulated and measured remote sensing data [34]. An example of a simulation steering approach was reported by Launay and Guerif [36]. In this study, the crop model was linked to a radiative transfer model through leaf area index (LAI) (crop model output) in order to simulate remote sensing observations. The results showed that after re-parametrization of the crop model, the relative error of the yield estimates of sugar beets significantly decreased. However the majority of studies used the forcing function approach, incorporating LAI values derived from remote sensing [32,33,37-41]. To obtain the LAI values, most of the studies inverted the observed relationship built using in situ-measured LAI and NDVI values calculated from the optical images [20,21,23]. For example, Dente et al., [42] showed that the assimilation of LAI derived from optical images acquired at the wheat heading stage reduced the root mean square error of 
yield estimates from 0.65 to $0.36 \mathrm{t} / \mathrm{h}$. Few studies assimilated the soil moisture in the crop model. Ines et al. [34] showed that the independent assimilation of LAI or soil moisture values slightly improved the maize yield simulated by a crop model, while the use of both LAI and soil moisture values more greatly improved the errors for the simulated maize yield.

With the arrival of new remote sensing radar satellites operating in C-band (SENTINEL-1A: launched on 3 April 2014, soon to be followed by SENTINEL-1B), and optical sensors (SENTINEL-2A: launched on 23 June 2015, soon to be followed by SENTINEL-2B), it will be possible to obtain SAR and optical data for global areas at high spatial and temporal resolutions (2 days with the two SENTINEL-1, and 5 days with the two SENTINEL-2 satellites, at a $10 \mathrm{~m}$ spatial resolution). This availability of both SENTINEL-1 satellites and SENTINEL-2 sensors in addition to LANDSAT-8 will allow the coupling of SAR and optical data in order to estimate soil moisture and vegetation parameters.

The main objective of this study was to develop an inversion technique based on neural networks to estimate soil surface moisture and leaf area index (LAI) in irrigated grasslands by combining fully polarimetric RADARSAT-2 C-band SAR and optical data. The benefits of having data in dual-polarization or in full-polarization mode for the SAR images were evaluated in comparison to the single-polarization mode. In addition, the use of polarimetric parameters, mainly Shannon entropy and Pauli components, was also studied.

The Shannon entropy (SE) is a measurement that was introduced by Réfrégier and Mario [43]. It measures the statistical disorder encountered in polarimetric SAR images. The highest values of SE indicate almost complete depolarization of the microwave beam. In remote sensing, this parameter is rarely used. Ziolkowski et al. [44] observed a very high correlation with the Shannon entropy for LAI-values between 0.4 and $2.6 \mathrm{~m}^{2} / \mathrm{m}^{2}$ (low SE-values correspond to lowest LAI). This correlation was significantly higher than the corresponding correlation of the LAI values with the backscattering coefficient for both $\mathrm{HH}$ and $\mathrm{HV}$ polarizations. Recently, Betbeder et al. [45] showed that the Shannon entropy is highly correlated with the fragmentation of hedgerows. The Pauli decomposition components corresponding to the three diagonal 
elements of the coherency matrix ([46]), each have a specific scattering mechanism: $(\mathrm{HH}+\mathrm{VV})$ represents the surface scattering, $(\mathrm{HV}+\mathrm{VH})$ is associated with volume scattering, and $(\mathrm{HH}-\mathrm{VV})$ indicates doublebounce scattering. Surface scattering dominates when the radar signal is primarily reflected from the canopy top. Volume scattering occurs when the meadow is full grown and the penetration of the radar signal through the canopy is allowed, while double bounce originates when the radar signal is reflected from the soil, then bounced at the stems. Studies found that the Pauli components are strong indicators of crop growth development. Jiao et al. [47] reported a significant correlation between volume scattering and the LAI for both corn and soybeans. Moran et al. [48] showed that the combined measurement of volume scattering and the double-bounce provided the maximum information about crop phenology due to different sensitivities to crop growth and reproductive stages. Recently, Liu et al. [49] found that both the Pauli double-bounce and volume scattering intensities for corn correlate well with the LAI (increase with increasing LAI).

To retrieve soil and canopy biophysical characteristics, several studies showed that neural networks were potentially more accurate than other estimation techniques (Regression, Bayes, Nelder-Mead) (e.g., [5053]). Studies noted that, for a highly accurate neural network, a training database representing a variety of soil and vegetation conditions is required (e.g., [54-55]). In addition, neural networks have been demonstrated to accurately approximate any relationship between the input and output parameters [56].

This work contributes to the preparation of the combined use of the new SENTINEL-1 SAR data with optical data obtained from the new LANDSAT-8 and SENTINEL-2 sensors. Section 2 describes the study site and the dataset. The inversion methodology is presented in section 3 . The results and discussion are provided in Section 4; and finally, Section 5 presents the main conclusions.

\section{STUDY AREA AND MEASUREMENTS}

\section{A. Study Area}

The study site was a 450 hectare farmland composed of irrigated and non-irrigated grassland for hay 
production. Located in southeastern France (center: $43.64^{\circ} \mathrm{N}, 5.01^{\circ} \mathrm{E}$, Figure 1 ), this relatively flat site is characterized by a Mediterranean climate, with a rainy season between September and November and an average cumulative rainfall between $350 \mathrm{~mm}$ and $800 \mathrm{~mm}$ [23]. The evaporation rate can reach $10 \mathrm{~mm} / \mathrm{day}$ during the summer season with a daily air temperature that reaches $35^{\circ} \mathrm{C}$ in July and August.

The top soil texture of the irrigated plots is a loam with a depth varying between $30 \mathrm{~cm}$ and $80 \mathrm{~cm}$. Moreover, the top soil is characterized by an small amount of pebbles. The grassland plots were level with a very gentle slope (approximately $0.3 \%$ ) to allow surface irrigation by gravity (border irrigation) between March and September for a few hours, approximately every 10 days on average. Irrigation was applied via canals which bring water to the highest extremities of the plots. They are harvested three times a year, in May, June and September.

\section{Insert Figure 1}

\section{B. Synthetic Aperture Radar images}

Eighteen SAR images were acquired by RADARSAT-2 operating in C-band (5.3 GHz), at different incidence angles (between $22^{\circ}$ and $47^{\circ}$ ), and in fine quad-polarization mode ( $\left.\mathrm{HH}, \mathrm{HV}, \mathrm{VH}, \mathrm{VV}\right)$. These images were acquired between July 2013 and September 2014 (Table 1) with a spatial resolution between $7.2 \mathrm{~m}$ and $14.6 \mathrm{~m}$. The PolSARPro v4.2.0 software (http://earth.eo.esa.int/polsarpro/) was used for processing the RADARSAT- 2 images $(7 \times 7$ boxcar filter $)$ in order to extract the different polarimetric layers (backscattering coefficients, entropy, anisotropy, etc.). Then, every generated layer was geocoded using the MapReady 2.3 software (http://www.asf.alaska.edu/downloads/software tools) and a Digital Elevation Model with a pixel spacing of $5 \mathrm{~m}$. The polarimetric parameters were then averaged over each reference grassland plot by using the values of all pixels within the reference plots. 


\section{Optical images}

Eighteen optical images were acquired by LANDSAT-7/8 over the study site (Table 1). The processing of the Optical images included orthorectification and correction for atmospheric effects. The atmospheric correction of the LANDSAT-8 images was carried out using the SMAC atmospheric correction method [57], and the atmospheric correction of the LANDSAT-7 images was directly performed by NASA (National Aeronautics and Space Administration) using the LEDAPS software. LANDSAT-7 surface reflectance data were downloaded from the USGS website (http://earthexplorer.usgs.gov/). The NDVI was then computed from the optical images and the NDVI values were averaged for each reference plot.

As the dates of the optical images were different from the SAR acquisition dates, the NDVI for each SAR acquisition date was estimated using a linear interpolation of the two NDVI-values calculated from optical images with acquisition dates preceding and succeeding the SAR image. This simple linear interpolation gave a good estimate because the optical images were regularly available.

\section{In situ measurements}

Simultaneously with the SAR acquisitions, in situ measurements of soil and vegetation parameters were collected on several reference plots (between seven and ten, Figure 2) in order to analyze the relationship between the information extracted from the radar and optical images $\left(\sigma^{\circ}\right.$, NDVI ...) and the soil and vegetation parameters (Table 1). The dimension of the reference plots ranged from 2.13 ha and 7.23 ha. In situ measurements were made within a 2-hour window around the SAR overpass time in order to minimize diurnal variation in vegetation and soil water content on radar backscatter.

\section{Insert Figure 2}

Between 25 and 30 volumetric soil moisture measurements $(m v)$ were performed in the first top $5 \mathrm{~cm}$ for each reference plot along regular transects using calibrated TDR (Time Domain Reflectometry) probes. 
The mean volumetric soil moisture was then calculated for each reference plot and each date. For reference plots under irrigation in which a high spatial heterogeneity of the soil moisture was observed, several homogenous areas within the reference plot were defined. During the ground campaign, the soil moisture content of the reference plots ranged between 13.5 and 40.9 vol. \% (Table 1).

Ten roughness profiles were made in each reference plot using a $1 \mathrm{~m}$ long needle-profilometer and a sampling interval of $2 \mathrm{~cm}$. From these roughness profiles, the root mean square $(\mathrm{rms})$ surface height and the correlation length $(L)$ were then calculated for each reference plot using the mean of all autocorrelation functions acquired for each reference plot. The rms surface height and the correlation length ranged, between $0.35 \mathrm{~cm}$ and $0.55 \mathrm{~cm}$, and between $2.00 \mathrm{~cm}$ and $4.60 \mathrm{~cm}$, respectively.

In situ measurements of vegetation parameters were also performed: the leaf area index (LAI), absorbed photosynthetically active radiation (FAPAR) and fraction of green vegetation cover (FCover), vegetation water content (VWC), fresh grassland biomass (BIO) and vegetation height (VEH) were measured. For each reference plot, 20 to 25 hemispherical digital photos were acquired at nadir. These photos were processed using CAN-EYE imaging software to obtain the LAI, FAPAR, and FCover (http://www6.paca.inra.fr/can-eye). Moreover, the fresh grassland biomass (wet weight per unit area) and the vegetation water content (wet weight - dry weight) were determined for each reference plot from four grass samples collected over a $50 \mathrm{~cm} \times 50 \mathrm{~cm}$ square. In addition, 30 vegetation height measurements were carried out for each reference plot. All vegetation measurements within each plot were averaged to provide a mean value for each plot. The LAI, BIO, VWC, VEH, were between 0.49 and $5.37 \mathrm{~m}^{2} / \mathrm{m}^{2}, 0.29$ and 2.88 $\mathrm{kg} / \mathrm{m}^{2}, 0.10$ and $2.39 \mathrm{~kg} / \mathrm{m}^{2}$, and between 7 and $93 \mathrm{~cm}$, respectively (Table 1).

\section{Insert Table 1}

\section{Methodology}

First, the soil moisture (mv) and the leaf area index (LAI) were estimated from the SAR and the optical 
in : IEEE Journal of Selected Topics in Applied Earth Observations and Remote Sensing, $n^{\circ}$ 99, 2015. p.1-15

images using neural networks (NN). Six inversion configurations of image layers were defined:

- Configuration 1: One polarization from the full polarized Radarsat-2 images (HH, HV, or VV) and the NDVI calculated from optical images (3 cases)

- Configuration 2: Two polarizations from Radarsat-2 images (HH and HV, HV and VV, or HH and VV) and the NDVI (3 cases).

- Configuration 3: Fully polarized Radarsat-2 images and the NDVI (1 case).

- Configuration 4: Co-polarizations, Shannon entropy, Pauli surface scattering (HH+VV), Pauli doublebounce (HH-VV), and NDVI (1 case).

- Configuration 5: Fully polarized Radarsat-2 images, Shannon entropy, Pauli components (HH+VV and HH-VV), and NDVI (1 case).

- Configuration 6: In this configuration, the relevance of in situ FAPAR and FCover was evaluated using the configuration among the configurations 1 to 3 with the lowest error for the estimation of $\mathrm{mv}$ and LAI. This corresponds to the following three cases: (1) SAR layers + FAPAR, (2) SAR layers + FCover, and (3) SAR layers + FAPAR + FCover + NDVI. In situ FAPAR and FCover were used because many studies showed that it is possible to derive the FAPAR and FCover of crops from optical images through a radiative transfer model with a relative uncertainty of approximately 5 and $20 \%$ for both FAPAR and FCover [37,58].

Next, the possibility of estimating soil moisture, LAI, biomass, vegetation height, and water vegetation content was studied using the image layers defined in configuration 4, then by adding in situ FAPAR and FCover layers.

The developed neural networks have only one hidden layer. The number of neurons associated with the hidden layer was determined by training the networks - 20 hidden neurons gave a good estimate of parameters.

For all of these configurations, the radar incidence angle was used as an input parameter in the neural networks. In fact, two approaches were utilized. For the first approach, the neural networks were built for 
each incidence angle. For the second approach, the neural networks were built using all of the incidence angles. Both approaches gave equivalent results, so the second approach was utilized.

The performance of the inversion technique based on the neural networks was analyzed for each configuration coupling SAR and optical data. The prediction error for the soil moisture and LAI was evaluated using a 5-fold cross-validation. To do the 5-fold cross-validation, the dataset was first randomly divided into 5 equal size subsets. Next, 4 of the subsets were used to train the NNs and one was retained to validate the NN predictions. The cross-validation process was then repeated 5 times, with each of the 5 subdatasets used exactly once as the validation data.

The final validation result combines the 5 validation results. The advantage of this method over repeated random sub-sampling is that all observations are used for both training and validation, and each observation is used for validation exactly once.

The training of neural networks using the $80 \%$ of the dataset composed of input and output vectors was accomplished to minimize the mean square error between the NN predictions and the reference values.

The use of a simple inversion technique based on a backscattering model such as the Water Cloud Model ([59]) was also tested. The results showed that the use of a simple inversion technique led to an inaccurate estimate of $\mathrm{mv}$ and LAI because several minima were sometimes found for the cost function with very close values.

Three statistical indicators were used to evaluate the consistency between estimated parameters and measured values: the root mean square error (RMSE), the mean bias (Bias), and the average relative error (ARE):

$$
\begin{aligned}
& \mathrm{RMSE}=\sqrt{\frac{1}{N} \sum_{i=1}^{N}\left(P_{i}^{\text {estimated }}-P_{i}^{\text {measured }}\right)^{2}} \\
& \mathrm{Bias}=\frac{1}{N} \sum_{i=1}^{N}\left(P_{i}^{\text {estimated }}-P_{i}^{\text {measured }}\right)
\end{aligned}
$$




$$
\mathrm{ARE}=\frac{1}{N} \sum_{i=1}^{N} \frac{\left|P_{i}^{\text {estimated }}-P_{i}^{\text {measured }}\right|}{P_{i}^{\text {measured }}}
$$

Where $\mathrm{P}$ is the estimated/measured parameter and $\mathrm{N}$ is the number of data points.

\section{RESULTS AND DISCUSSION}

\section{A. Correlation analysis between parameters of the dataset}

The analysis of in situ measurements showed that the biomass increases linearly with the vegetation height (Figure 3a). For a vegetation height (VEH) higher than $40 \mathrm{~cm}$, the fresh grassland biomass (BIO) showed strong variation. For example, the BIO values were between 1 and $3 \mathrm{~kg} / \mathrm{m}^{2}$ and $60 \mathrm{~cm}$ for VEH. Grassland plots contained approximately 20 different species of vegetation. An important change in vegetation morphology was observed, especially for grass species, when the vegetation exceeded approximately 40 $\mathrm{cm}$; inclined elements (panicle, small leave, etc.) randomly oriented at the top of the plant began to appear. The change in morphology led to the observed fluctuation in the correlation between VEH and BIO for VEH values higher than $50 \mathrm{~cm}$. The in situ LAI increased with BIO for BIO values lower than $1 \mathrm{~kg} / \mathrm{m}^{2}$ (Figure 3b). For BIO values greater than $1 \mathrm{~kg} / \mathrm{m}^{2}$, a high variation in the LAI values was observed.

Results showed that the NDVI calculated from optical images was related to the in situ LAI by an exponential function $[23,60]$ characterized by a strong increase of NDVI for LAI-values lower than $3 \mathrm{~m}^{2} / \mathrm{m}^{2}$ (Figure 3c). For high LAI-values (LAI $>3 \mathrm{~m}^{2} / \mathrm{m}^{2}$ ), NDVI was almost constant (approximately 0.85 ). In addition, the results showed that the NDVI increased with the BIO to a threshold of approximately $1 \mathrm{~kg} / \mathrm{m}^{2}$; beyond this threshold, the NDVI appears to be independent of BIO (Figure 3d). This behavior was also observed between the NDVI and both the vegetation water content (VWC) and the vegetation height with a threshold approximately $1 \mathrm{~kg} / \mathrm{m}^{2}$ for VWC and $20 \mathrm{~cm}$ for VEH.

The relationships between FAPAR and LAI and between FCover and LAI showed a stronger dependence between the two parameters than that observed between NDVI and LAI (Figures 3e and 3f). While the 
NDVI was saturated for LAI values up to $3 \mathrm{~m}^{2} / \mathrm{m}^{2}$, FAPAR and FCover showed a smaller increase with LAI for LAI values up to $4 \mathrm{~m}^{2} / \mathrm{m}^{2}$. This observation allows a better estimate of LAI using FAPAR or FCover instead of NDVI.

\section{Insert Figure 3}

\section{B. Sensitivity of the radar signal to soil moisture}

The sensitivity of the C-band SAR signal to soil moisture was studied for two biomass classes: BIO $<1$ $\mathrm{kg} / \mathrm{m}^{2}$ and $\mathrm{BIO}>1 \mathrm{~kg} / \mathrm{m}^{2}$. The mean backscattering coefficient was calculated from calibrated Radarsat-2 images for each reference plot by averaging the linear $\sigma^{\circ}$ values of all pixels.

The radar signal was plotted for $\mathrm{HH}, \mathrm{VV}$ and $\mathrm{HV}$ polarizations separately for each incidence angle range (Figure 4). The results show that the radar signal was clearly dependent on soil moisture, with high sensitivity to soil moisture for a BIO lower than $1 \mathrm{~kg} / \mathrm{m}^{2}$. In addition, this sensitivity was higher for $\mathrm{HH}$ than for VV and HV polarizations (Figure 4). Finally, the sensitivity of the radar incidence angle to soil moisture seems to be similar for all incidences used in this study (between $22^{\circ}$ and $47^{\circ}$ ).

\section{Insert Figure 4}

\section{Sensitivity of radar signal to LAI}

In this section, the sensitivity of C-band SAR signal to the leaf area index was analyzed for $\mathrm{HH}$, VV and HV polarizations separately for each incidence angle range (Figure 5). To reduce the effect of soil moisture on the analysis of the backscattered radar signal, the relationship between the radar signals and the LAI were plotted for two classes of soil moisture ( $\mathrm{mv}<25$ and $\mathrm{mv}>25 \mathrm{vol} . \%)$.

The results showed that for soil moisture values lower than 25 vol. $\%$ and incidence angles of $22^{\circ}-23^{\circ}$, the radar signal of $\mathrm{HH}$ and VV polarizations was negatively correlated with the LAI for LAI values lower than $2 \mathrm{~m}^{2} / \mathrm{m}^{2}$, and increased with an increase in LAI from 2 to $5.5 \mathrm{~m}^{2} / \mathrm{m}^{2}$ (Figure $5 \mathrm{a}, 5 \mathrm{~b}$ ). For mv values higher 
than 25 vol. $\%$ and incidence angles of $22^{\circ}-23^{\circ}$, the radar signal did not appear to depend on the LAI for all polarizations (Figure 5a-5c). The decrease in the radar signal for an LAI lower than $2 \mathrm{~m}^{2} / \mathrm{m}^{2}$ is related to an increase in the attenuation of the soil contribution, which is more important than the enhanced contribution from the vegetation canopy [61-63]. In addition, the increase in the vegetation contribution as a function of the LAI combined with the decrease in the soil moisture contribution (mv lower than 25 vol.\%) resulted in a slight increase in the radar backscatter with LAI for values greater than $2 \mathrm{~m}^{2} / \mathrm{m}^{2}$. For mv values higher than $25 \mathrm{vol} \%$, the decrease of the soil contribution when LAI was increased to between 0.1 and $5.0 \mathrm{~m}^{2} / \mathrm{m}^{2}$ was of the same order as the increase of the vegetation contribution. For the other configurations (incidence angles of $22^{\circ}-23^{\circ}$ and $\mathrm{HV}$, incidence angles of $28^{\circ}, 38^{\circ}, 43^{\circ}$ and $47^{\circ}$ and all polarizations) the dependence between the radar signal and the LAI was not observed (Figure 5d-5i).

Many studies have analyzed the behavior of radar signals ( $\mathrm{Ku}, \mathrm{X}, \mathrm{C}$ and $\mathrm{L}$ bands) as a function of LAI [60, 64-67]. Previous results have shown that the radar signal decreased with an increase in the LAI for narrow leaf crops (grassland, wheat, alfalfa, and barley), and increased for board leaf crops (sunflower, corn, sorghum, and sugarcane) [66-67]. For example, Champion [64] studied the sensitivity of a radar signal in the $\mathrm{C}$ band to the LAI of wheat crops (soil moisture values between 5 and 20 vol.\%) using $\mathrm{HH}$ and VV polarizations $\left(20^{\circ}\right)$. The results showed that the backscattering coefficient in C-band decreased for LAI values between 0.1 and $4 \mathrm{~m}^{2} / \mathrm{m}^{2}$ and then increased for LAI values up to $8 \mathrm{~m}^{2} / \mathrm{m}^{2}$. Fieuzal et al. [65] analyzed wheat crops with LAI values between 1 and $4 \mathrm{~m}^{2} / \mathrm{m}^{2}$ under wet soil conditions (soil moistures between 20 and 40 vol.\%). The radar signals in the $\mathrm{X}$ and $\mathrm{C}$ bands decreased with the LAI by approximately $-2.6 \mathrm{~dB}$ by $1 \mathrm{~m}^{2} / \mathrm{m}^{2}$ for $\mathrm{X}-\mathrm{HH}$ and $-2.4 \mathrm{~dB}$ by $1 \mathrm{~m}^{2} / \mathrm{m}^{2}$ for $\mathrm{C}-\mathrm{VV}$. The $\mathrm{C}-\mathrm{HH}$ and $\mathrm{C}-\mathrm{HV}$ signals had a lower sensitivity, with about $-1 \mathrm{~dB}$ by $1 \mathrm{~m}^{2} / \mathrm{m}^{2}$. Ulaby et al. [68] demonstrated that the radar signal at $\mathrm{Ku}-\mathrm{VV}$ $\left(50^{\circ}\right)$ increased with the LAI of corn and sorghum, up to an LAI of approximately $2 \mathrm{~m}^{2} / \mathrm{m}^{2}$; beyond this, the radar signal was saturated.

\section{Insert Figure 5}




\section{Estimation of soil moisture and vegetation parameters}

\section{1) Soil moisture and LAI estimates}

\section{Soil moisture estimates}

The results show that the best estimate of soil moisture (mv) was obtained when the HH polarization was used (Table 2). An accuracy of the mv estimates of 5.75 vol.\% was reached when $\mathrm{HH}$ was combined with NDVI (ARE on $\mathrm{mv}$ of 20.3\%). The accuracy of the mv estimates was approximately 7 vol.\% (ARE approximately 26\%) using the two other mono-polarization configurations (HV or VV). Figure 6a shows a good estimate of the soil moisture with $\mathrm{HH}$ for the entire range of mv-values (between 10 and 45 vol.\%). With HV or VV, the soil moisture was over-estimated for mv-values between 10 and 25 vol. $\%$ and underestimated for mv-values between 25 and 45 vol.\% (Figures $6 \mathrm{~b}$ and $6 \mathrm{c}$ ). Figures $6 \mathrm{~d}$ to $6 \mathrm{f}$ show that the use of information other than $\mathrm{HH}$ and NDVI did not improve the estimation of mv (Table 2). Several results confirmed that the $\mathrm{HH}$ polarization was the best radar configuration for soil moisture estimates $[69,70]$. In addition, it was found that over bare agriculture fields, the backscattering coefficient was more sensitive to volumetric soil moisture in $\mathrm{HH}$ and VV than in the HV polarization [71]. When compared with the results obtained with a single polarization ( $\mathrm{HH}$ or $\mathrm{HV})$, the use of two polarizations $(\mathrm{HH}$ and $\mathrm{HV}$ ) did not lead to a significant improvement in soil moisture estimate (less than 1 vol.\% in the C- and X-bands ([72-73]). In vegetated areas, our results showed better accuracy with $\mathrm{HH}$ polarization for retrieving soil moisture in comparison to $\mathrm{HV}$ and $\mathrm{VV}$ polarizations because the $\mathrm{HH}$ polarization was less affected by vegetation than VV and HV (vertical vegetation geometry).

The use of the dual-polarization (two polarizations) or full-polarization (three polarizations) modes did not improve the estimate of mv compared with $\mathrm{HH}$ alone (approximately 5.8 vol.\% for $\mathrm{HH}+\mathrm{HV}$ or $\mathrm{HH}+\mathrm{VV}$, 6.1 vol.\% for $\mathrm{HH}+\mathrm{HV}+\mathrm{VV}$, and 6.7 vol.\% for $\mathrm{VV}+\mathrm{HV}$ ) (Table 2). In addition, the use of polarimetric parameters as Shannon entropy, Pauli surface scattering and Pauli double-bounce did not improve the mv estimate (approximately 6 vol.\%) (Table 2). This is the same conclusion that was arrived at when other 
in : IEEE Journal of Selected Topics in Applied Earth Observations and Remote Sensing, $n^{\circ}$ 99, 2015. p.1-15

information (i.e., FAPAR and FCover extracted from optical images) was used (Table 2). This result confirmed that the use of information with low sensitivity to soil moisture (HV or/and VV) in addition to one polarization with high sensitivity to soil moisture $(\mathrm{HH})$ does not improve the soil moisture estimate.

The analysis of the error of the mv estimates according to NDVI-values showed that for a NDVI lower than $0.7\left(\mathrm{LAI}<2.5 \mathrm{~m}^{2} / \mathrm{m}^{2}\right)$, the estimate of mv was better than $1.5 \mathrm{vol} . \%$ as compared to plots with a NDVI higher than 0.7 (case HH+NDVI : RMSE=4.7 vol.\% for NDVI $<0.7$ against 6.2 vol.\% for NDVI $>0.7$ ). This result confirmed that the soil contribution in $\mathrm{C}$-band remained important when the vegetation cover was dense (i.e., high values of LAI, BIO, VWC, VEH) and that the soil component could be used to estimate the soil moisture with acceptable accuracy.

Based on the values of BIO, VWC and VEH, the mv estimates showed that the RMSE was slightly better for thin vegetation covers (RMSE=5.2 vol.\%, with $\mathrm{HH}+\mathrm{LAI}$ for $\mathrm{BIO}<1 \mathrm{~kg} / \mathrm{m}^{2}, \mathrm{VWC}<0.8 \mathrm{~kg} / \mathrm{m}^{2}$ and $\mathrm{VEH}<30 \mathrm{~cm}$ ) than for dense vegetation covers $\left(\mathrm{RMSE}=6.2 \mathrm{vol} . \%\right.$ for $\mathrm{BIO}>1 \mathrm{~kg} / \mathrm{m}^{2}, \mathrm{VWC}>0.8 \mathrm{~kg} / \mathrm{m}^{2}$ and $\mathrm{VEH}>30 \mathrm{~cm})$.

In addition, the error on the mv estimates was of the same order for incidences between $22^{\circ}$ to $43^{\circ}$ $(\mathrm{RMSE}=5.8$ vol.\% with $\mathrm{HH}+\mathrm{NDVI})$ and was much lower than that obtained with an incidence of $47^{\circ}$ $(\mathrm{RMSE}=9.2 \mathrm{vol} . \%$ with $\mathrm{HH}+\mathrm{NDVI})$. This result confirmed that the soil component of the backscattering coefficient is low at a higher incidence angle $\left(47^{\circ}\right)$, making the inversion of the soil moisture less accurate.

This analysis confirmed the potential of small and medium radar incidences for estimating soil moisture $[72,74,75]$. The results obtained with an incidence of $47^{\circ}$ also showed that the estimated mv-values were approximately 25 vol. $\%$ for measured soil moistures between 10 and 45 vol.\% (mv was over-estimated for $\mathrm{mv}<25 \mathrm{vol} . \%$ and under-estimated for $\mathrm{mv}>25 \mathrm{vol} . \%)$.

\section{Insert Table 2}

\section{Insert Figure 6}


in : IEEE Journal of Selected Topics in Applied Earth Observations and Remote Sensing, $n^{\circ}$ 99, 2015. p.1-15

\section{LAI estimates}

The use of radar signals associated with NDVI gave the same accuracy for the estimation of LAI regardless of the radar information used (RMSE approximately $0.61 \mathrm{~m}^{2} / \mathrm{m}^{2}$ and ARE approximately $18 \%$ ) (Table 2). The use of in situ FAPAR or FCover improved the precision of the LAI estimates with an RMSE approximately $0.45 \mathrm{~m}^{2} / \mathrm{m}^{2}$ (RMSE $=0.44$ and $0.47 \mathrm{~m}^{2} / \mathrm{m}^{2}$ in using FAPAR and FCover, respectively). The simultaneous use of NDVI, FAPAR, and FCover with SAR information led to better accuracy of the estimation of LAI with an RMSE of $0.37 \mathrm{~m}^{2} / \mathrm{m}^{2}$ and ARE of $11.7 \%$ (Table 2). Figure 7 shows that the LAI values less than $4 \mathrm{~m}^{2} / \mathrm{m}^{2}$ can be estimated. Beyond that threshold, LAI values are under-estimated with estimated values between 3 and $4 \mathrm{~m}^{2} / \mathrm{m}^{2}$.

As shown in Figures 4 and 7, the radar signal is poorly correlated with LAI, while the information calculated from optical imagery (NDVI, FAPAR and FCover) shows a strong dependence on LAI. The inversion results confirm this observation because the accuracy for soil moisture estimates is of the same order regardless of the polarization. The accuracy for the soil moisture estimates depends only on the optical data parameter employed.

The inversion configurations using NDVI in addition to SAR information without FAPAR and FCover provide an error on LAI estimates much lower for NDVI $<0.7$ than for NDVI $>0.7$ with a RMSE of approximately $0.40 \mathrm{~m}^{2} / \mathrm{m}^{2}$ for NDVI $<0.7$ and approximately $0.70 \mathrm{~m}^{2} / \mathrm{m}^{2}$ for NDVI $>0.7$. The RMSE for the LAI estimates is of the same order (approximately $0.40 \mathrm{~m}^{2} / \mathrm{m}^{2}$ ) for both a NDVI lower and higher than 0.7 when FAPAR or FCover are used in addition to the SAR images. Finally, the error of the LAI estimates is independent of the radar incidence angle (between $22^{\circ}$ and $47^{\circ}$ in this study).

\section{Insert Figure 7}

\section{2) Soil moisture, LAI, biomass, VWC and VEH estimates}

The estimation of soil moisture and different vegetation parameters from a neural network combining as in 
in : IEEE Journal of Selected Topics in Applied Earth Observations and Remote Sensing, $n^{\circ}$ 99, 2015. p.1-15

input, HH, VV, Shannon entropy, Pauli surface scattering, double bounce Pauli and NDVI layers was performed with an RMSE of 5.78 vol. $\%, 0.59 \mathrm{~m}^{2} / \mathrm{m}^{2}, 0.47 \mathrm{~kg} / \mathrm{m}^{2}, 0.37 \mathrm{~kg} / \mathrm{m}^{2}$, and $13.87 \mathrm{~cm}$, respectively, on mv, LAI, BIO, VWC, and VEH (Table 3). The addition of FAPAR and FCover information to the NN input, led to similar performances for all of the estimated parameters except for LAI estimates for which the RMSE was better $\left(\mathrm{RMSE}=0.37\right.$ instead of $\left.0.59 \mathrm{~m}^{2} / \mathrm{m}^{2}\right)$.

The results for the mv and LAI estimates were similar to those obtained if the neural network was used to estimate the mv and LAI alone (Tables 2 and 3). The inversion approach provides a good estimate of the biomass and vegetation water content for BIO and VWC values lower than 2 and $1.5 \mathrm{~kg} / \mathrm{m}^{2}$, respectively (Figures $8 \mathrm{c}$ and $8 \mathrm{~d}$ ). Based on the range of biomass values, the RMSE of BIO estimates was $0.38 \mathrm{~kg} / \mathrm{m}^{2}$ for $\mathrm{BIO}<2 \mathrm{~kg} / \mathrm{m}^{2}$ and $0.75 \mathrm{~kg} / \mathrm{m}^{2}$ for $\mathrm{BIO}>2 \mathrm{~kg} / \mathrm{m}^{2}$. In addition, high under-estimation was observed for BIO>

$2 \mathrm{~kg} / \mathrm{m}^{2}$ (Bias $=-0.65 \mathrm{~kg} / \mathrm{m}^{2}$ against $+0.13 \mathrm{~kg} / \mathrm{m}^{2}$ for $\mathrm{BIO}<2 \mathrm{~kg} / \mathrm{m}^{2}$ ) (Figure 8c). The same result was obtained on VWC estimates with RMSE of $0.32 \mathrm{~kg} / \mathrm{m}^{2}$ for $\mathrm{VWC}<1.5 \mathrm{~kg} / \mathrm{m}^{2}$ and $0.58 \mathrm{~kg} / \mathrm{m}^{2}$ for VWC $>1.5$ $\mathrm{kg} / \mathrm{m}^{2}$ (Figure 8d). A high underestimation was also observed for $\mathrm{VWC}>1.5 \mathrm{~kg} / \mathrm{m}^{2}\left(\mathrm{Bias}=-0.49 \mathrm{~kg} / \mathrm{m}^{2}\right.$ against $+0.10 \mathrm{~kg} / \mathrm{m}^{2}$ for $\left.\mathrm{VWC}<1.5 \mathrm{~kg} / \mathrm{m}^{2}\right)$. Finally, the estimation of vegetation height $(\mathrm{VEH})$ was carried out with an RMSE of $13.45 \mathrm{~cm}$ (Table 3, Figure 8e).

\section{Insert Figure 8}

\section{CONCLUSION}

The objective of this study was to assess the capacity of coupling SAR and optical data to estimate soil moisture and vegetation parameters for irrigated grasslands. Radarsat-2 and Landsat 7/8 were used to assess the relevance of variables extracted from SAR (backscattering coefficient, polarimetric information) and optical images (NDVI, FAPAR and FCover) for retrieving soil moisture, leaf area index, biomass, vegetation water content, and vegetation height.

Inversion techniques based on neural networks were developed. The influence of the radar polarization on the estimation error of soil and vegetation parameters was studied by analyzing the mono-, dual- and full- 
in : IEEE Journal of Selected Topics in Applied Earth Observations and Remote Sensing, $n^{\circ}$ 99, 2015. p.1-15

polarization modes. In addition, the effect of the polarimetric parameters (Shannon entropy and Pauli components) on the inversion technique was also analyzed. Finally, configurations using NDVI, FAPAR and FCover data were also tested.

This study investigated the potential of combining data from the new Sentinel-1 SAR sensor (offering a global revisit time of just six days with the SENTINEL-1 constellation) and from both the new LANDSAT 8 (16 days revisit time) and the future SENTINEL-2 optical sensors, which provide systematic coverage of all lands with a revisit time of 10 days with one satellite, and 5 days with two. The need for hydrological and agricultural communities in terms of the temporal resolution of the new remote sensing sensors could be satisfied.

The main results obtained in this study can be summarized as follows:

- $\quad \mathrm{HH}$ polarization is the most relevant information among the SAR layers

- Dual or full polarization modes do not improve the estimation of soil moisture and vegetation parameters.

- The use of polarimetric parameters (Shannon entropy and Pauli components) does not improve the estimation of soil moisture and vegetation parameters.

- The 6 vol.\% RMSE on soil moisture estimates was obtained even for dense vegetation covers (LAI approximately $5 \mathrm{~m}^{2} / \mathrm{m}^{2}$, biomass approximately $3 \mathrm{~kg} / \mathrm{m}^{2}$, vegetation water content approximately 2.5 $\mathrm{kg} / \mathrm{m}^{2}$, vegetation height approximately $\left.1 \mathrm{~m}\right)$.

- $\quad$ The use of FAPAR and FCover only improved the estimate of the leaf area index (LAI) with an RMSE for the LAI of approximately $0.37 \mathrm{~m}^{2} / \mathrm{m}^{2}$ against $0.6 \mathrm{~m}^{2} / \mathrm{m}^{2}$ when NDVI was used.

- Biomass, vegetation water content and vegetation height were estimated with an accuracy of approximately $0.44 \mathrm{~kg} / \mathrm{m}^{2}, 0.36 \mathrm{~kg} / \mathrm{m}^{2}$ and $13.45 \mathrm{~cm}$, respectively. The average relative error for these three parameters was $34.2 \%, 45.5 \%$ and $39.1 \%$, respectively. 
in : IEEE Journal of Selected Topics in Applied Earth Observations and Remote Sensing, $n^{\circ}$ 99, 2015. p.1-15

- Under-estimation was observed for LAI, BIO and VWC higher than $4 \mathrm{~m}^{2} / \mathrm{m}^{2}, 2 \mathrm{~kg} / \mathrm{m}^{2}$ and $1.5 \mathrm{~kg} / \mathrm{m}^{2}$, respectively $\left(0.56 \mathrm{~m}^{2} / \mathrm{m}^{2}\right.$ on LAI estimates, $-0.65 \mathrm{~kg} / \mathrm{m}^{2}$ on $\mathrm{BIO}$ estimates and $-0.49 \mathrm{~kg} / \mathrm{m}^{2}$ on VWC estimates).

- The error of the LAI estimates is independent of the radar incidence angle (between $22^{\circ}$ and $47^{\circ}$ in this study).

\section{ACKNOWLEDGMENT}

This research was supported by IRSTEA (National Research Institute of Science and Technology for

Environment and Agriculture) and the French Space Study Center (CNES, TOSCA 2015). Mohammad El Hajj is a PhD student fellow of the Islamic development bank. The authors wish to thank CSA (Canadian Space Agency) for kindly providing RADARSAT-2 (SOAR-E Project 5141). The authors wish to thank François Charron and Gilles Belaud (SupAgro, UMR G-EAU) for kindly facilitate access to the study site.

\section{REFERENCES}

1. Chaves, M. M.; Oliveira, M. M. Mechanisms underlying plant resilience to water deficits: prospects for water-saving agriculture. J. Exp. Bot. 2004, 55, 2365-2384.

2. Sauer, T.; Havlík, P.; Schneider, U. A.; Schmid, E.; Kindermann, G.; Obersteiner, M. Agriculture and resource availability in a changing world: The role of irrigation. Water Resour. Res. $2010,46$.

3. Merot, A.; Wery, J.; Isberie, C.; Charron, F. Response of a plurispecific permanent grassland to border irrigation regulated by tensiometers. Eur. J. Agron. 2008, 28, 8-18.

4. Chen, G.; Fan, W.; Xu, X.; Deng, M. Monitoring of degrading grassland based on HJ-1A-HSI image. In IGARSS; 2013; pp. 800-803.

5. Gherboudj, I.; Magagi, R.; Berg, A. A.; Toth, B. Soil moisture retrieval over agricultural fields from multi-polarized and multi-angular RADARSAT-2 SAR data. Remote Sens. Environ. 2011, 115, 33-43. 
6. He, B.; Xing, M.; Bai, X. A Synergistic Methodology for Soil Moisture Estimation in an Alpine Prairie Using Radar and Optical Satellite Data. Remote Sens. 2014, 6, 10966-10985.

7. Prevot, L.; Champion, I.; Guyot, G. Estimating surface soil moisture and leaf area index of a wheat canopy using a dual-frequency (C and X bands) scatterometer. Remote Sens. Environ. 1993, 46, 331339.

8. De Roo, R. D.; Du, Y.; Ulaby, F. T.; Dobson, M. C. A semi-empirical backscattering model at L-band and C-band for a soybean canopy with soil moisture inversion. Geosci. Remote Sens. IEEE Trans. On 2001, 39, 864-872.

9. Sikdar, M.; Cumming, I. A modified empirical model for soil moisture estimation in vegetated areas using SAR data. In Geoscience and Remote Sensing Symposium, 2004. IGARSS'04. Proceedings. 2004 IEEE International; IEEE: Anchorage, AK, 2004; Vol. 2, pp. 803-806.

10. Wang, S. G.; Li, X.; Han, X. J.; Jin, R. Estimation of surface soil moisture and roughness from multiangular ASAR imagery in the Watershed Allied Telemetry Experimental Research (WATER). Hydrol. Earth Syst. Sci. 2011, 15, 1415-1426.

11. Yang, G.; Shi, Y.; Zhao, C.; Wang, J. Estimation of soil moisture from multi-polarized SAR data over wheat coverage areas. In Agro-Geoinformatics (Agro-Geoinformatics), 2012 First International Conference on; IEEE: Shanghai, China, 2012; pp. 1-5.

12. Yu, F.; Zhao, Y. A new semi-empirical model for soil moisture content retrieval by ASAR and TM data in vegetation-covered areas. Sci. China Earth Sci. 2011, 54, 1955-1964.

13. Zribi, M.; Chahbi, A.; Shabou, M.; Lili-Chabaane, Z.; Duchemin, B.; Baghdadi, N.; Amri, R.; Chehbouni, A. Soil surface moisture estimation over a semi-arid region using ENVISAT ASAR radar data for soil evaporation evaluation. Hydrol. Earth Syst. Sci. 2011, 15.

14. Arii, M. Retrieval of soil moisture under vegetation using polarimetric radar. Ph.D. dissertation, California Inst. Technol., Pasadena, CA, 2009. http://resolver.caltech.edu/CaltechETD:etd-05082009$\underline{143935}$ 
15. Van Zyl, J.J.; Kim, Y. Synthetic Aperture Radar Polarimetry, John Wiley \& Sons, Inc., Hoboken, NJ, USA, 2011. doi: 10.1002/9781118116104.

16. Miernecki, M.; Wigneron, J.P.; Lopez-Baeza, E.; Kerr, Y.; De Jeu, R.; De Lannoy, G.J.M., Kackson, T.J.; O’Neil, P.E.; Schwank, M.; Moran, R.F.; Bircher, S.; Lawrence, H.; Mialon, A.; Al Bitar, A.; Richaume, Ph.; Comparison of SMOS and SMAP soil moisture retrieval approaches using tower-based radiometer data over a vineyard field. Remote Sensing of Environment, 2014, 154, 89-101.

17. Gao, S.; Niu, Z.; Huang, N.; Hou, X. Estimating the Leaf Area Index, height and biomass of maize using HJ-1 and RADARSAT-2. Int. J. Appl. Earth Obs. Geoinformation 2013, 24, 1-8.

18. Baghdadi, N.; Boyer, N.; Todoroff, P.; El Hajj, M.; Bégué, A. Potential of SAR sensors TerraSAR-X, ASAR/ENVISAT and PALSAR/ALOS for monitoring sugarcane crops on Reunion Island. Remote Sens. Environ. 2009, 113, 1724-1738.

19. Inoue, Y.; Sakaiya, E.; Wang, C. Capability of C-band backscattering coefficients from high-resolution satellite SAR sensors to assess biophysical variables in paddy rice. Remote Sens. Environ. 2014, 140, 257-266.

20. Baret, F.; Guerif, M. Remote detection and quantification of plant stress: opportunities remote sensing observations. In Comparative Biochemistry and Physiology a-Molecular \& Integrative Physiology; ELSEVIER SCIENCE INC 360 PARK AVE SOUTH, NEW YORK, NY 10010-1710 USA, 2006 ; Vol. 143, pp. S148-S148.

21. Baret, F.; Hagolle, O.; Geiger, B.; Bicheron, P.; Miras, B.; Huc, M.; Berthelot, B.; Niño, F.; Weiss, M.; Samain, O. LAI, fAPAR and fCover CYCLOPES global products derived from VEGETATION: Part 1: Principles of the algorithm. Remote Sens. Environ. 2007, 110, 275-286.

22. Bsaibes, A.; Courault, D.; Baret, F.; Weiss, M.; Olioso, A.; Jacob, F.; Hagolle, O.; Marloie, O.; Bertrand, N.; Desfond, V. Albedo and LAI estimates from FORMOSAT-2 data for crop monitoring. Remote Sens. Environ. 2009, 113, 716-729. 
23. Courault, D.; Hadria, R.; Ruget, F.; Olioso, A.; Duchemin, B.; Hagolle, O.; Dedieu, G. Combined use of FORMOSAT-2 images with a crop model for biomass and water monitoring of permanent grassland in Mediterranean region. Hydrol. Earth Syst. Sci. Discuss. 2010, 7, 1731-1744.

24. Courault, D.; Bsaibes, A.; Kpemlie, E.; Hadria, R.; Hagolle, O.; Marloie, O.; Hanocq, J.-F.; Olioso, A.; Bertrand, N.; Desfonds, V. Assessing the potentialities of FORMOSAT-2 data for water and crop monitoring at small regional scale in South-Eastern France. Sensors 2008, 8, 3460-3481.

25. Edirisinghe, A.; Hill, M. J.; Donald, G. E.; Hyder, M. Quantitative mapping of pasture biomass using satellite imagery. Int. J. Remote Sens. 2011, 32, 2699-2724.

26. Ferreira, L. G.; Fernandez, L. E.; Sano, E. E.; Field, C.; Sousa, S. B.; Arantes, A. E.; Araújo, F. M. Biophysical properties of cultivated pastures in the Brazilian savanna biome: An analysis in the spatialtemporal domains based on ground and satellite data. Remote Sens. 2013, 5, 307-326.

27. Schino, G.; Borfecchia, F.; De Cecco, L.; Dibari, C.; Iannetta, M.; Martini, S.; Pedrotti, F. Satellite estimate of grass biomass in a mountainous range in central Italy. Agrofor. Syst. 2003, 59, 157-162.

28. Todd, S. W.; Hoffer, R. M.; Milchunas, D. G. Biomass estimation on grazed and ungrazed rangelands using spectral indices. Int. J. Remote Sens. 1998, 19, 427-438.

29. Chen, D.; Huang, J.; Jackson, T. J. Vegetation water content estimation for corn and soybeans using spectral indices derived from MODIS near-and short-wave infrared bands. Remote Sens. Environ. 2005, $98,225-236$.

30. Payero, J. O.; Neale, C. M. U.; Wright, J. L. Comparison of eleven vegetation indices for estimating plant height of alfalfa and grass. Appl. Eng. Agric. 2004, 20, 385-393.

31. Monod, H.; Naud, C.; Makowski, D. Uncertainty and sensitivity analysis for crop models. Work. Dyn. Crop Models Eval. Anal. Parameterization Appl. 2006, 4, 55-100.

32. Di Bella, C.; Faivre, R.; Ruget, F.; Seguin, B. Using VEGETATION satellite data and the crop model STICS-Prairie to estimate pasture production at the national level in France. Phys. Chem. Earth Parts $A B C 2005,30,3-9$. 
33. Jongschaap, R. E. Run-time calibration of simulation models by integrating remote sensing estimates of leaf area index and canopy nitrogen. Eur. J. Agron. 2006, 24, 316-324.

34. Ines, A. V.; Das, N. N.; Hansen, J. W.; Njoku, E. G. Assimilation of remotely sensed soil moisture and vegetation with a crop simulation model for maize yield prediction. Remote Sens. Environ. 2013, 138, $149-164$.

35. Dorigo, W. A.; Zurita-Milla, R.; de Wit, A. J.; Brazile, J.; Singh, R.; Schaepman, M. E. A review on reflective remote sensing and data assimilation techniques for enhanced agroecosystem modeling. Int. J. Appl. Earth Obs. Geoinformation 2007, 9, 165-193.

36. Launay, M.; Guerif, M. Assimilating remote sensing data into a crop model to improve predictive performance for spatial applications. Agric. Ecosyst. Environ. 2005, 111, 321-339.

37. Claverie, M.; Vermote, E. F.; Weiss, M.; Baret, F.; Hagolle, O.; Demarez, V. Validation of coarse spatial resolution LAI and FAPAR time series over cropland in southwest France. Remote Sens. Environ. 2013, 139, 216-230.

38. Duchemin, B.; Hagolle, O.; Mougenot, B.; Simonneaux, V.; Benhadj, I.; Hadria, R.; Ezzahar, J.; Hoedges, J.; Khabba, S.; Kharrou, M. H. Agrometerological study of semi-arid areas: an experiment for analysing the potential of FORMOSAT-2 time series of images in the Marrakech plain. Int J Remote Sens 2008, 29, 5291-300.

39. Fieuzal, R.; Duchemin, B.; Jarlan, L.; Zribi, M.; Baup, F.; Merlin, O.; Hagolle, O.; Garatuza-Payan, J. Combined use of optical and radar satellite data for the monitoring of irrigation and soil moisture of wheat crops. Hydrol. Earth Syst. Sci. 2011, 15, 1117-1129.

40. Hadria, R.; Duchemin, B.; Baup, F.; Le Toan, T.; Bouvet, A.; Dedieu, G.; Le Page, M. Combined use of optical and radar satellite data for the detection of tillage and irrigation operations: Case study in Central Morocco. Agric. Water Manag. 2009, 96, 1120-1127.

41. Duchemin, B.; Hadria, R.; Erraki, S.; Boulet, G.; Maisongrande, P.; Chehbouni, A.; Escadafal, R.; Ezzahar, J.; Hoedjes, J. C. B.; Kharrou, M. H. Monitoring wheat phenology and irrigation in Central 
in : IEEE Journal of Selected Topics in Applied Earth Observations and Remote Sensing, $n^{\circ}$ 99, 2015. p.1-15

Morocco: On the use of relationships between evapotranspiration, crops coefficients, leaf area index and remotely-sensed vegetation indices. Agric. Water Manag. 2006, 79, 1-27.

42. Dente, L.; Satalino, G.; Mattia, F.; Rinaldi, M. Assimilation of leaf area index derived from ASAR and MERIS data into CERES-Wheat model to map wheat yield. Remote Sens. Environ. 2008, 112, 13951407.

43. Réfrégier, P.; Mario, J. Shannon entropy of partially polarized and partially coherent light with Gaussian fluctuations. Journal of the Optical Society of America A, 2006, vol. 23, no. 12, 3036-3044.

44. Ziolkowski, D.; Malek, I.; Budzynska, M. Dual Polarimetric signatures of vegetation: a case study Biebrza. Geoinformation Issues, 2013, vol. 5, no. 1 (5), 29-41.

45. Betbeder, J.; Nabucet, J.; Pottier, E.; Baudry, J.; Corgne, S.; Hubert-Moy, L. Detection and characterization of hedgerows using TerraSAR-X imagery. Remote Sensing, 2014, 6, 3752-3769.

46. Cloude, S.R.; Pottier, E. A review of target decomposition theorems in radar polarimetry. IEEE Transactions on Geoscience and Remote Sensing, 1996, 34 (2), 498-518.

47. Jiao, X.; McNairn, H.; Shang, J.; Pattey, E.; Liu, J.; Champagne, C. The sensitivity of RADARSAT-2 polarimetric SAR data to corn and soybean leaf area index. Journal Canadien de Télédétection, 2011, 37(1), pp. 69-81.

48. Moran, M.S.; Alonso, L.; Moreno, J.F. ; Pilar Cendrero Mateo, M. ; Fernando de la Cruz, D. ; Montoro, A. A RADARSAT-2 Quad-Polarized Time Series for Monitoring Crop and Soil Conditions in Barrax, Spain. IEEE Transactions on Geoscience and Remote Sensing, 2012, vol. 50, issue 4, 1057 - 1070.

49. Liu, C.; Shang, J.; Vachon, P.W.; McNairn, H._Multiyear crop monitoring using polarimetric RADARSAT-2 data. », IEEE Transactions on Geoscience and Remote Sensing, 2013, 51(4), 2227-2240.

50. Paloscia, S.; Pampaloni, P.; Pettinato, S.; Santi, E. A comparison of algorithms for retrieving soil moisture from ENVISAT/ASAR images. IEEE Trans. Geosci. Remote Sens, 2008, 46(10), 3274-3284. 
51. Verger, A.; Baret, F.; Camacho, F. Optimal modalities for radiative transfer-neural network estimation of canopy biophysical characteristics: Evaluation over an agricultural area with CHRIS/PROBA observations. Remote Sensing of Environment, 2011, 115, 415-426.

52. Baghdadi, N.; Cresson, R.; El Hajj, M.; Ludwig, R.; La Jeunesse, I.. Estimation of soil parameters over bare agriculture areas from C-band polarimetric SAR data using neural networks. Hydrology and Earth System Sciences (HESS), 2012, 16, 1607-1621, doi:10.5194/hess-16-1607-2012.

53. Paloscia, S.; Pettinato, S.; Santi, E.; Notarnicola, C.; Pasolli, L.; Reppucci, A. Soil moisture mapping using Sentinel-1 images: Algorithm and preliminary validation. Remote Sensing of Environnment, 2013, $134,234-248$.

54. Schlerf, M.; Atzberger, C. Inversion of a forest reflectance model to estimate structural canopy variables from hyperspectral remote sensing data. Remote Sensing of Environment, 2006, 100, 281-294.

55. Santi, E.; Paloscia, S.; Pettinato, S.; Notarnicola, C.; Pasolli, L.; Pistocchi, A. Comparison between SAR Soil Moisture Estimates and Hydrological Model Simulations over the Scrivia Test Site. Remote Sensing, 2013, 5(10), 4961-4976.

56. Krasnopolsky, V.M. ; Chevallier, F. Some neural network applications in environmental sciences. Part II: Advancing computational efficiency of environmental models. Neural Networks, 2003, 16, 335-348.

57. Rahman, H.; Dedieu, G. SMAC: a simplified method for the atmospheric correction of satellite measurements in the solar spectrum. International Journal of Remote Sensing, 1994, 15, 123-143.

58. North, P.R. Estimation of FAPAR, LAI, and vegetation fractional cover from ATSR-2 imagery. Remote Sensing of Environment, , 2002, 80, 114-121.

59. Attema, E.P.W.; Ulaby, F.T. Vegetation modeled as a water cloud. Radio Sci., 1978, 13, 357-364.

60. Hajj, M. E.; Baghdadi, N.; Belaud, G.; Zribi, M.; Cheviron, B.; Courault, D.; Hagolle, O.; Charron, F. Irrigated grassland monitoring using a time series of terraSAR-X and COSMO-skyMed X-Band SAR Data. Remote Sens. 2014, 6, 10002-10032. 
61. Balenzano, A.; Mattia, F.; Satalino, G.; Davidson, M. Dense temporal series of C-and L-band SAR data for soil moisture retrieval over agricultural crops. Sel. Top. Appl. Earth Obs. Remote Sens. IEEE J. 2011, $4,439-450$.

62. Brown, S.C.; Quegan, S.; Morrison, K.; Bennett, J.C.; Cookmartin, G. High-resolution measurements of scattering in wheat canopies-Implications for crop parameter retrieval. Geosci. Remote Sens. IEEE Trans. 2003, 41, 1602-1610.

63. Mattia, F.; le Toan, T.; Picard, G.; Posa, F.I.; D’Alessio, A.; Notarnicola, C.; Gatti, A.M.; Rinaldi, M.; Satalino, G.; Pasquariello, G. Multitemporal C-band radar measurements on wheat fields. IEEE Trans. Geosci. Remote Sens. 2003, 41, 1551-1560.

64. Champion, I. Etude et mise au point de modèles Semi-empiriques représentant la réponse de couverts végétaux dans le domaine hyperfréquence. Complémentarité avec le domaine optique, Thèse de Doctorat, Université Paris VII, Paris, France, 1991.

65. Fieuzal, R.; Baup, F.; Marais-Sicre, C. Monitoring wheat and rapeseed by using synchronous optical and radar satellite data-From temporal signatures to crop parameters estimation. Adv. Remote Sens. 2013, 2, 162-180.

66. Macelloni, G.; Paloscia, S.; Pampaloni, P.; Marliani, F.; Gai, M. The relationship between the backscattering coefficient and the biomass of narrow and broad leaf crops. IEEE Trans. Geosci. Remote Sens. 2001, 39, 873-884.

67. Fontanelli, G.; Paloscia, S.; Zribi, M.; Chahbi, A. Sensitivity analysis of X-band SAR to wheat and barley leaf area index in the Merguellil Basin. Remote Sens. Lett. 2013, 4, 1107-1116.

68. Ulaby, F.T.; Allen, C.T.; Eger Iii, G.; Kanemasu, E. Relating the microwave backscattering coefficient to leaf area index. Remote Sens. Environ. 1984, 14, 113-133.

69. Beaudoin, A.; Le Toan, T.; Gwyn, Q. H. J. SAR observations and modeling of the C-band backscatter variability due to multiscale geometry and soil moisture. Geosci. Remote Sens. IEEE Trans. On 1990, $28,886-895$. 
in : IEEE Journal of Selected Topics in Applied Earth Observations and Remote Sensing, $n^{\circ}$ 99, 2015. p.1-15

70. Toan, L. Active microwave signatures of soil and crops- Significant results of three years of experiments. In 1982 International Geoscience and Remote Sensing Symposium, Munich, West Germany; 1982; p. 1982.

71. Baghdadi, N.; Cerdan, O.; Zribi, M.; Auzet, V.; Darboux, F.; El Hajj, M.; Bou Keir R. Operational performance of current synthetic aperture radar sensors in mapping soil surface characteristics: application to hydrological and erosion modelling. Hydrological Processes, 2008, vol. 22, Issue 1, 9-20.

72. Baghdadi, N.; Holah, N.; Zribi, M. Soil moisture estimation using multi-incidence and multi-polarization ASAR data. Int. J. Remote Sens. 2006, 27, 1907-1920.

73. Baghdadi, N.; Aubert, M.; Zribi, M. Use of TerraSAR-X data to retrieve soil moisture over bare soil agricultural fields. IEEE Geoscience and Remote Sensing Letters, 2012, vol. 9, no. 3, 512-516.

74. Baghdadi, N.; King, C.; Bourguignon, A.; Remond, A. Potential of ERS and Radarsat data for surface roughness monitoring over bare agricultural fields: application to catchments in Northern France. Int. J. Remote Sens. 2002, 23, 3427-3442.

75. Baghdadi, N.; Zribi, M.; Loumagne, C.; Ansart, P.; Anguela, T. P. Analysis of TerraSAR-X data and their sensitivity to soil surface parameters over bare agricultural fields. Remote Sens. Environ. 2008, $112,4370-4379$. 


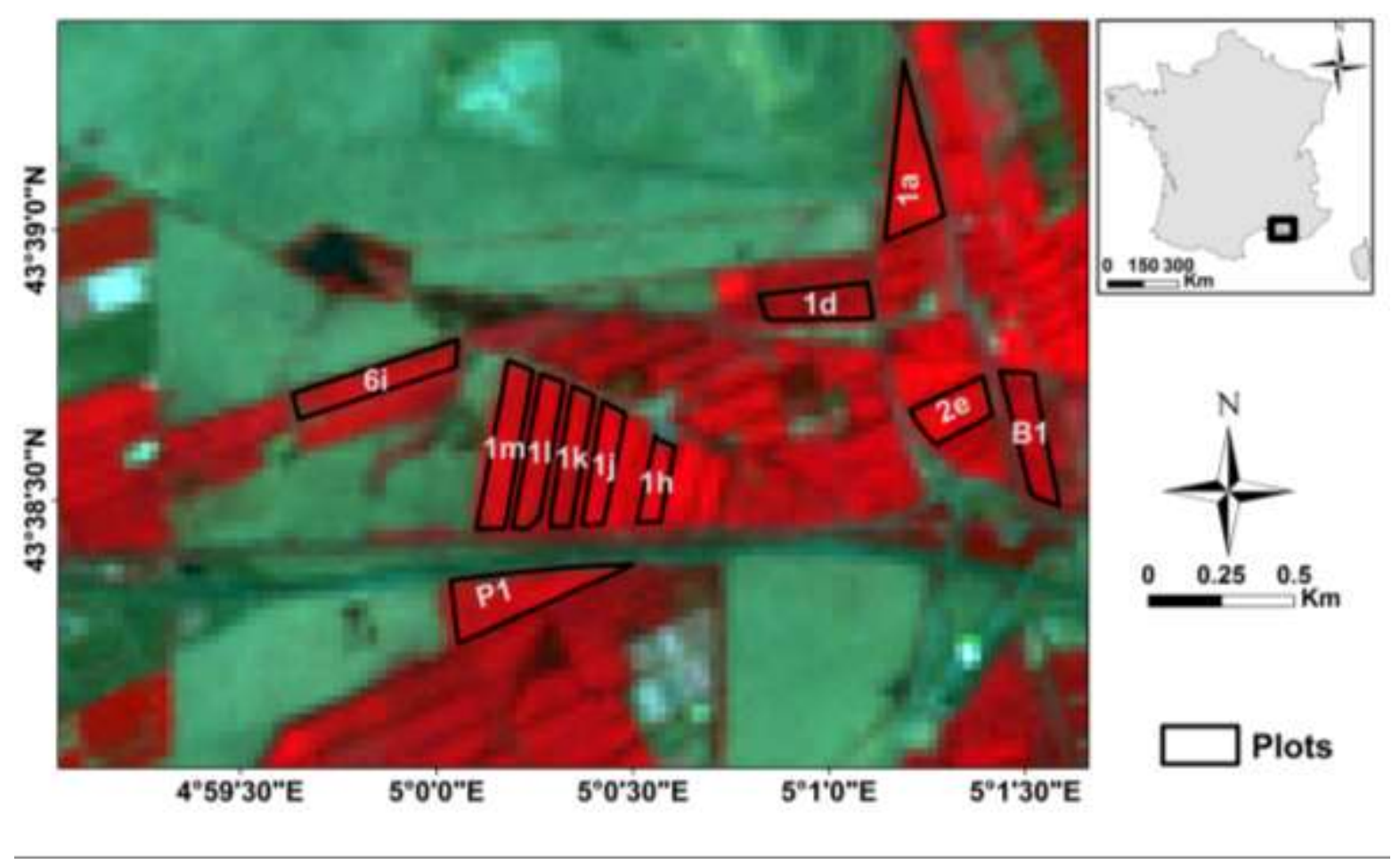

Fig. 1. Location of the study site (Domaine du Merle). Black polygons delineate the reference plots. Background is Landsat 7 image acquired on 11 September 2014 in RGB colors (Red: NIR, Green: R, Blue: G).

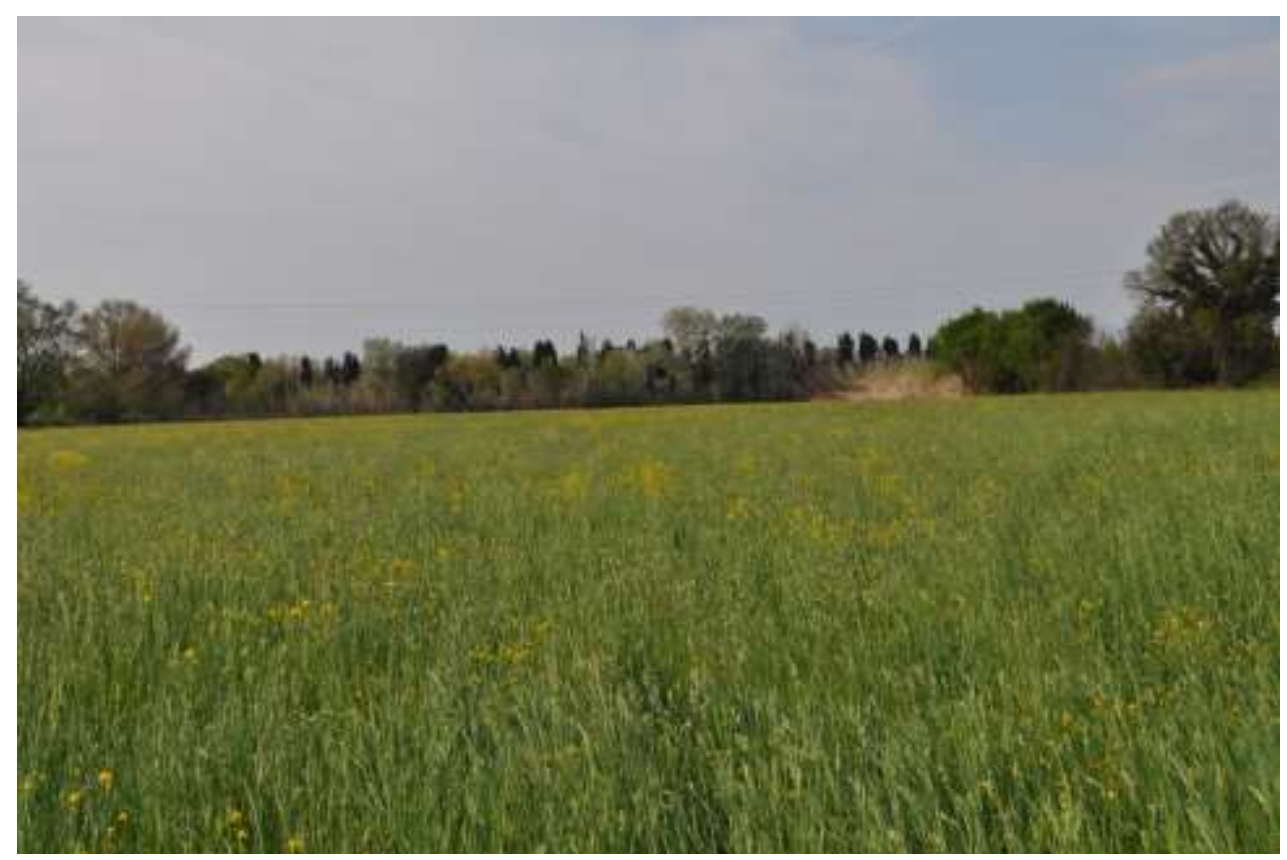

Figure 2: A grassland plot. 


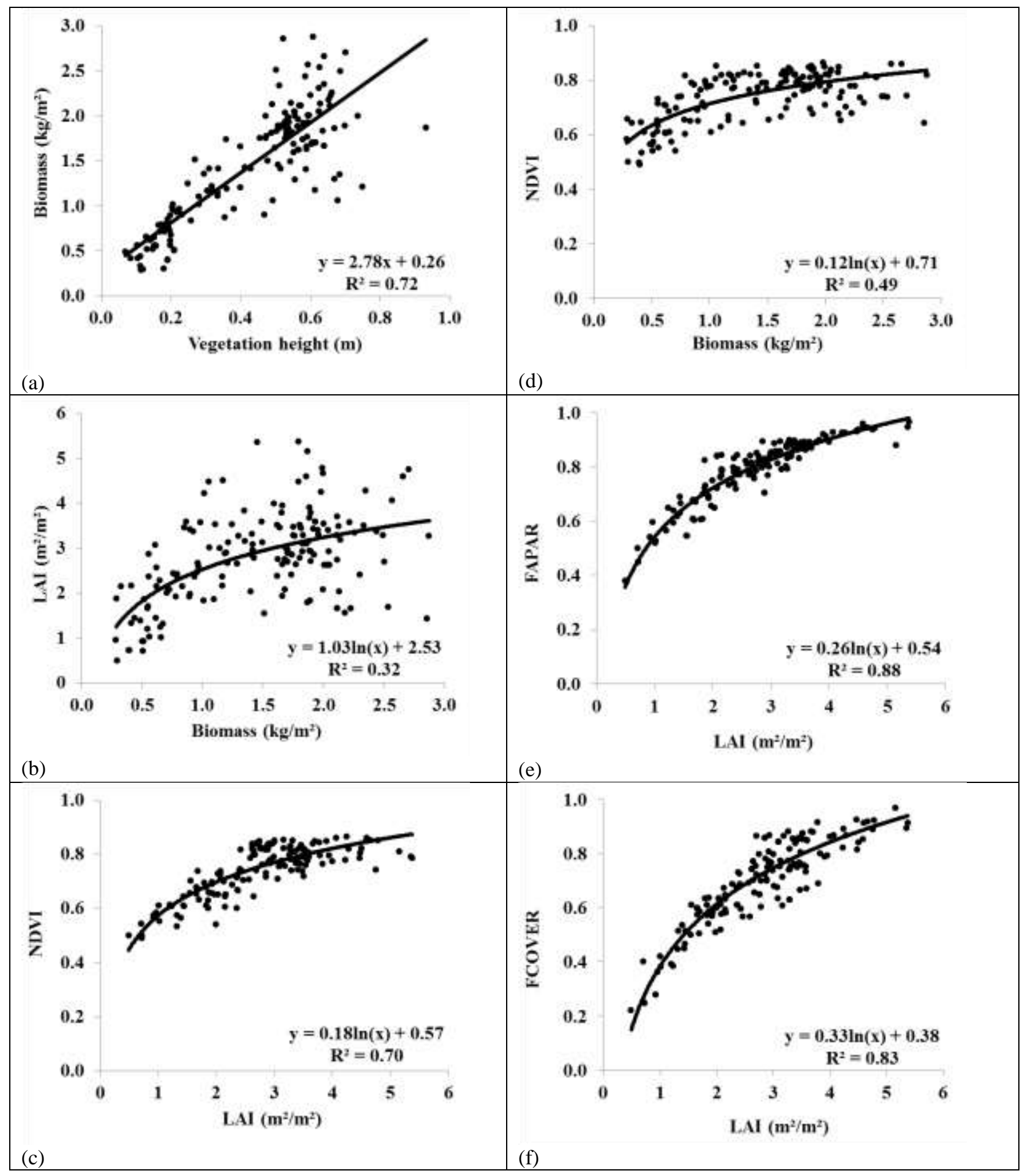

Fig. 3. Relationship between (a) in situ biomass and vegetation height, (b) in situ biomass and vegetation water content, (c) NDVI calculated from optical images (SPOT 4/5 and LANDSAT 7/8) and in situ LAI, (d) NDVI and biomass, (e) FAPAR and in situ LAI, (f) FCOVER and in situ LAI. 


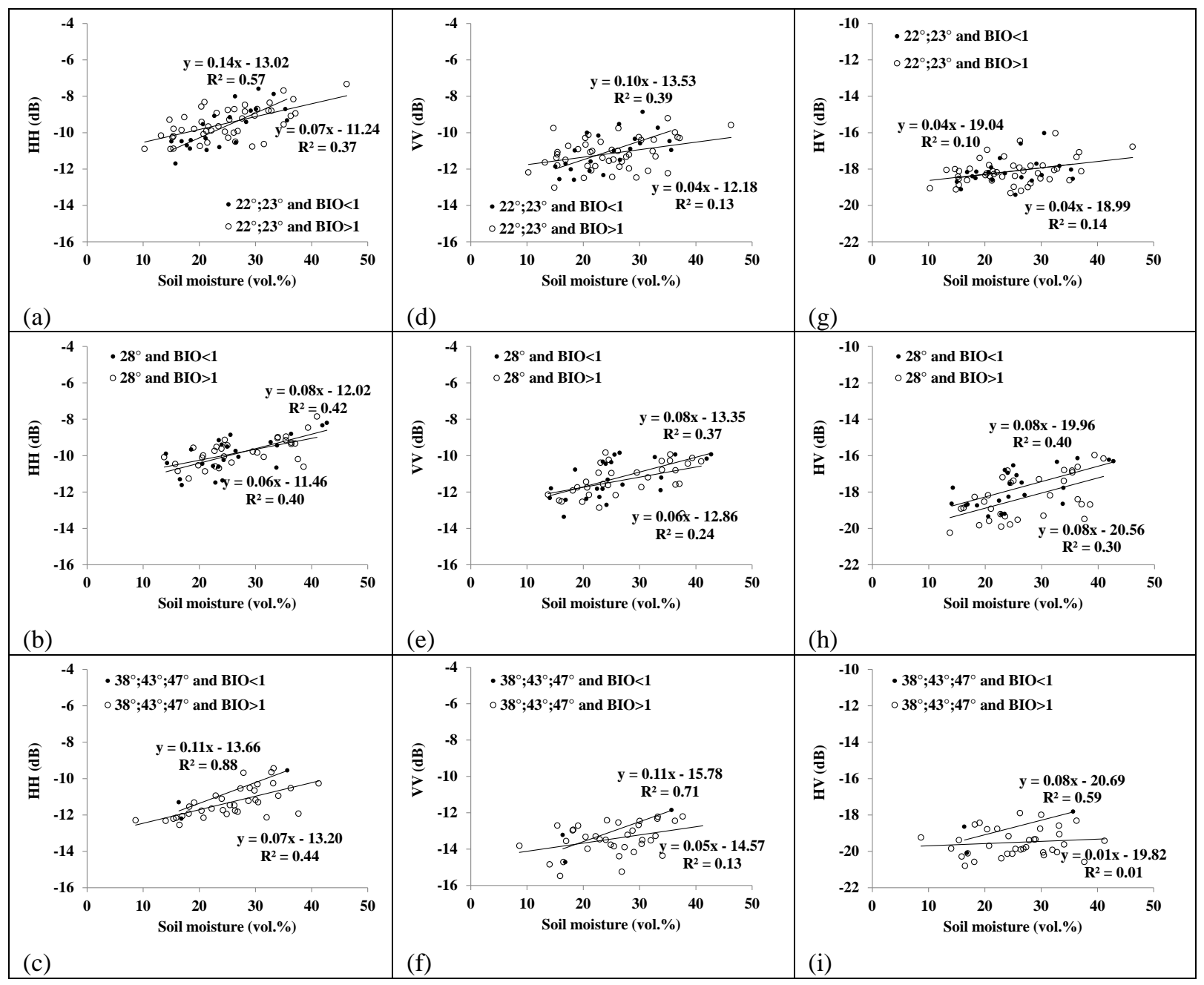

Fig. 4. Relationship between Radarsat-2 backscattering coefficients and soil moisture. 


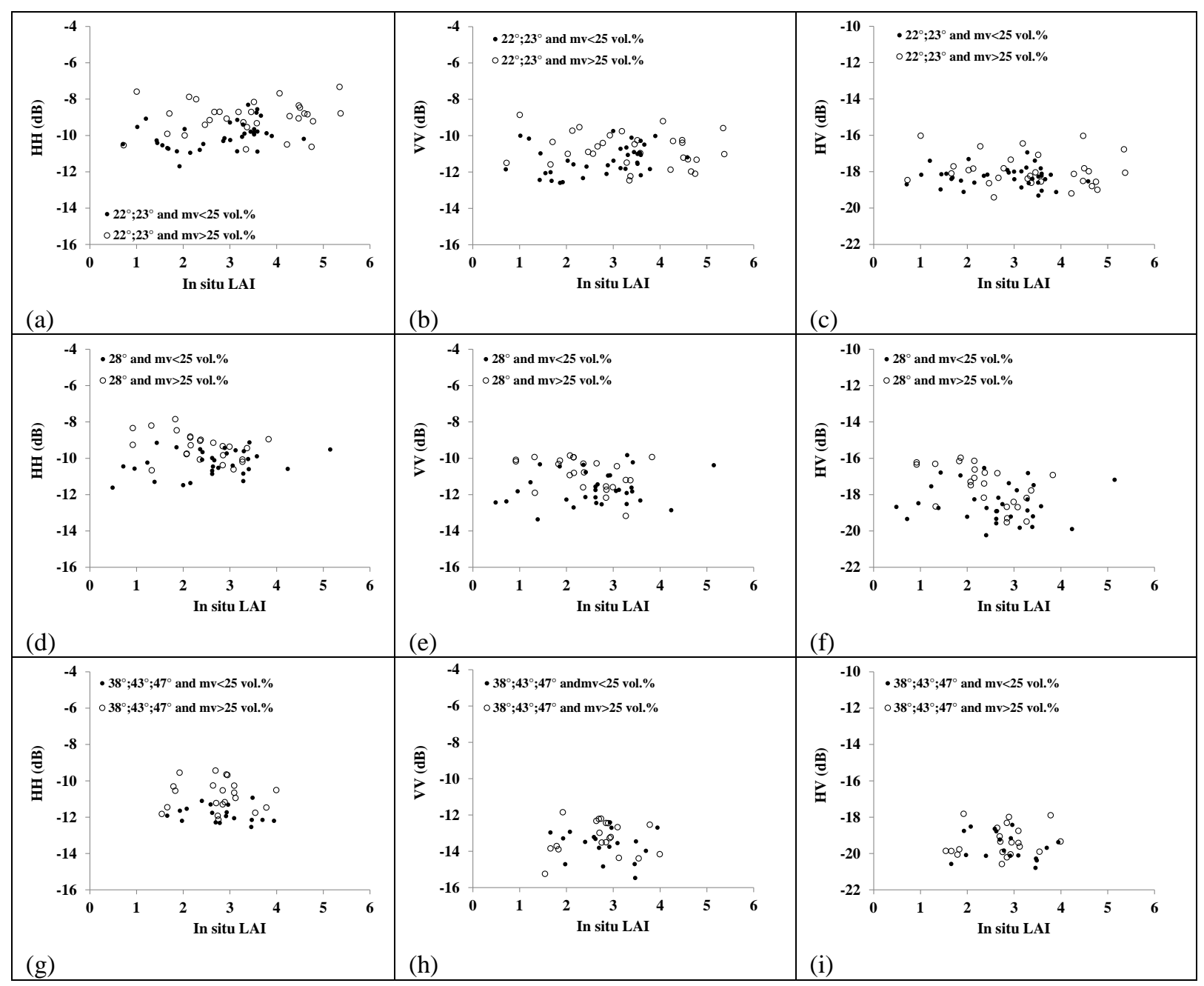

Fig. 5. Relationship between Radarsat-2 backscattering coefficients and Leaf Area Index (LAI). 


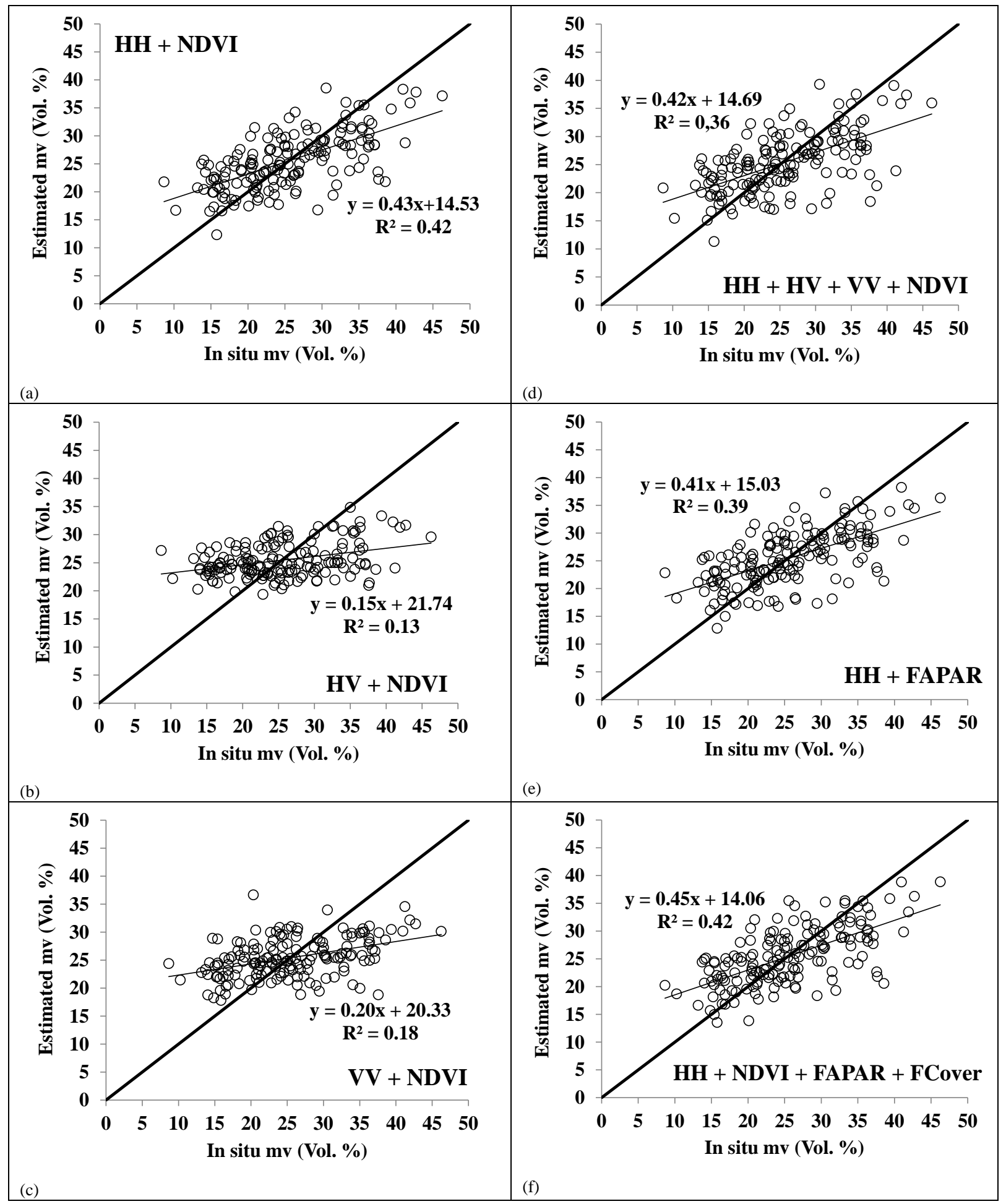

Fig. 6. Comparison between estimated soil moisture (mv) using neural networks and measured soil moisture for some SAR and optical coupling configurations. 


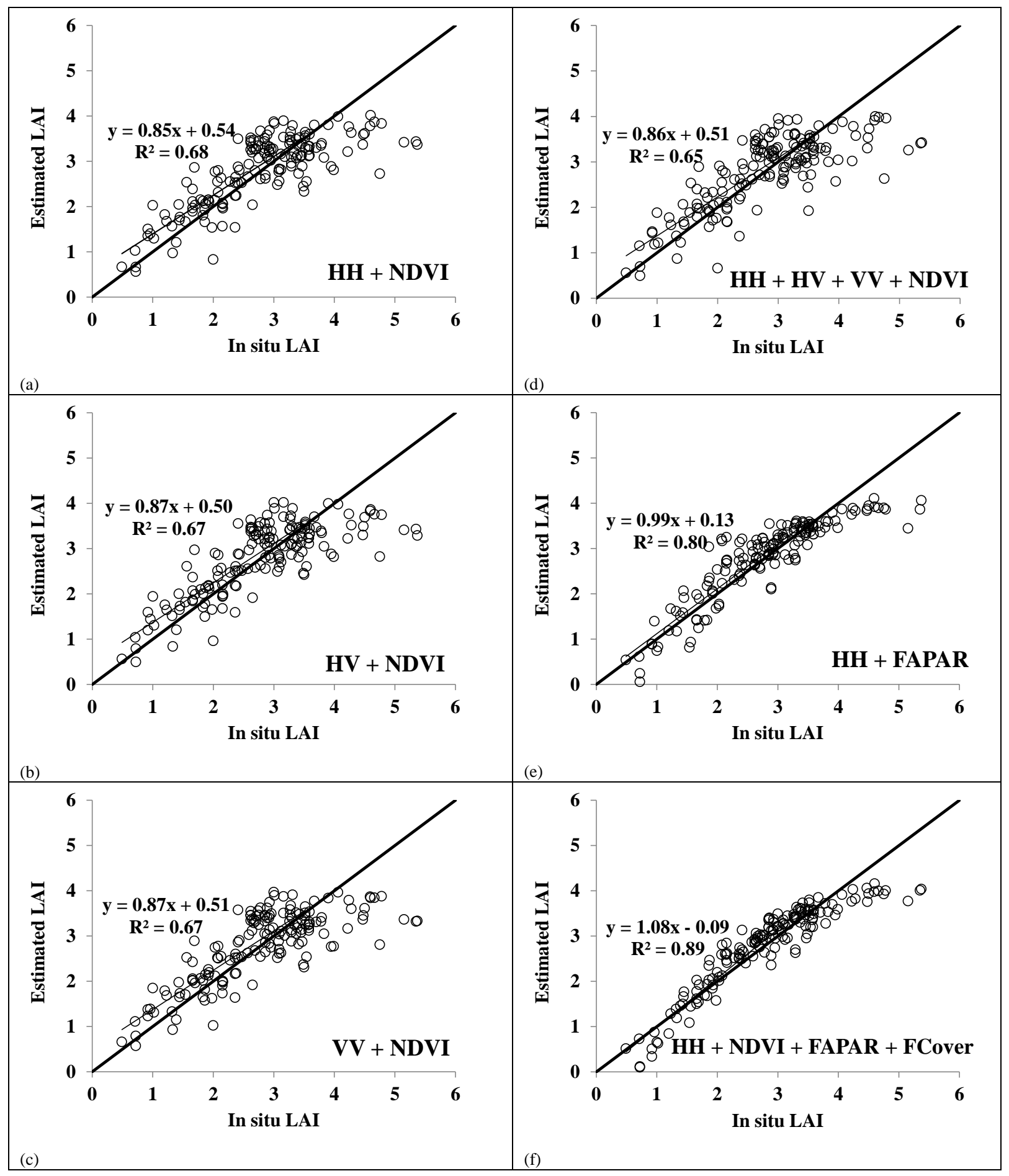

Fig. 7. Comparison between estimated LAI using neural networks and measured LAI for some SAR and optical coupling configurations. Regression equations and determination coefficients were calculated for LAI values lower than $4 \mathrm{~m}^{2} / \mathrm{m}^{2}$. 


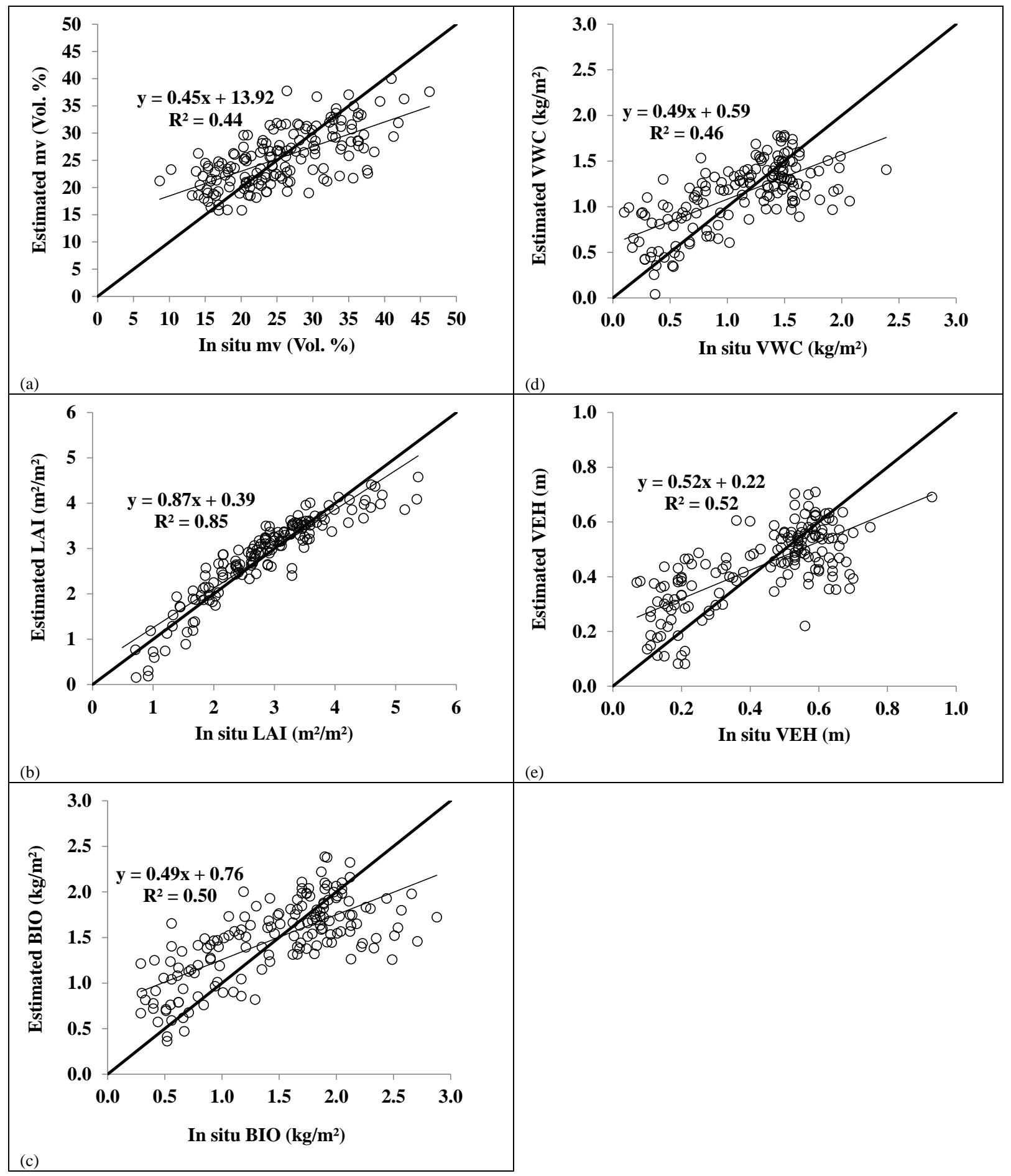

Fig. 8. Comparison between estimated and measured soil moisture, LAI, biomass (BIO), vegetation water content (VWC) and vegetation height (VEH) using neural networks combining HH, VV, Shannon entropy, Pauli surface scattering, Pauli double-bounce, NDVI, FAPAR, FCover. 
TABLE 1

MAIN CHARACTERISTICS OF RADARSAT-2 (RS2), OPTICAL IMAGES, AND IN SITU MEASUREMENTS USED IN THIS STUDY

$\theta$ : radar incidence angle $\left({ }^{\circ}\right)$, mv: volumetric soil moisture (vol.\%), VWC vegetation water content $\left(\mathrm{kg} / \mathrm{m}^{2}\right)$, BIO: vegetation biomass $\left(\mathrm{kg} / \mathrm{m}^{2}\right)$, VEH vegetation height $(\mathrm{m})$, LAI: Leaf Area Index $\left(\mathrm{m}^{2} / \mathrm{m}^{2}\right)$.

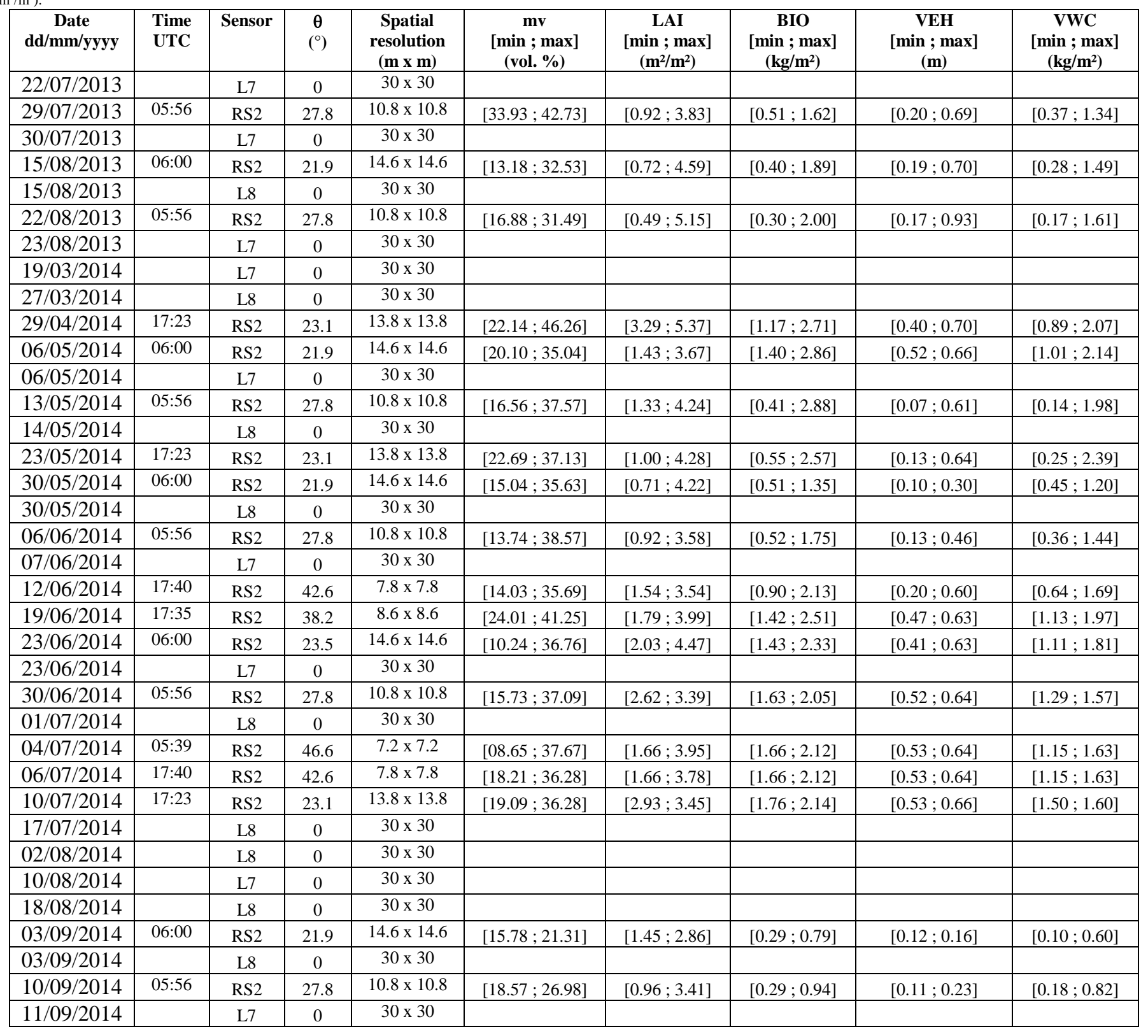

TABLE 2

STATISTICS ON THE ESTIMATION OF SOIL MOISTURE (MV IN VOL. \% $)$ AND LAI USING NEURAL NETWORKS. BIAS $=$ ESTIMATED - IN SITU, SE $=$

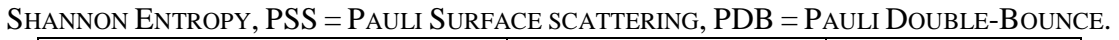

\begin{tabular}{|c|c|c|}
\hline Configuration & $\begin{array}{c}\text { Bias (vol.\%)/ RMSE } \\
(\text { vol.\%)/ARE (\%) } \\
\text { on mv }\end{array}$ & $\begin{array}{c}\text { Bias }\left(\mathbf{m}^{2} / \mathbf{m}^{2}\right) / \text { RMSE } \\
\left(\mathbf{m}^{2} / \mathbf{m}^{2}\right) / \text { ARE }(\%) \\
\text { on LAI }\end{array}$ \\
\hline HH, NDVI & $0.03 / 5.75 / 20.3$ & $0.01 / 0.60 / 18.3$ \\
\hline HV, NDVI & $-0.02 / 7.04 / 26.3$ & $0.00 / 0.61 / 18.4$ \\
\hline VV, NDVI & $-0.07 / 6.82 / 25.1$ & $0.00 / 0.61 / 18.4$ \\
\hline $\mathrm{HH}, \mathrm{HV}, \mathrm{NDVI}$ & $-0.03 / 5.77 / 20.1$ & $0.01 / 0.61 / 18.6$ \\
\hline $\mathrm{HH}, \mathrm{VV}, \mathrm{NDVI}$ & $-0.04 / 5.80 / 20.2$ & $0.00 / 0.60 / 17.8$ \\
\hline VV, HV , NDVI & $0.06 / 6.72 / 25.1$ & $0.01 / 0.61 / 18.5$ \\
\hline $\mathrm{HH}, \mathrm{HV}, \mathrm{VV}, \mathrm{NDVI}$ & $-0.14 / 6.08 / 20.8$ & $-0.01 / 0.62 / 18.5$ \\
\hline $\mathrm{HH}, \mathrm{VV}, \mathrm{SE}, \mathrm{PSS}, \mathrm{PDB}, \mathrm{NDVI}$ & $0.04 / 5.96 / 21.1$ & $-0.01 / 0.62 / 18.7$ \\
\hline HH, HV , VV , SE, PSS , PDB , NDVI & $0.00 / 5.86 / 21.0$ & $0.00 / 0.59 / 18.8$ \\
\hline HH, FAPAR & $-0.07 / 5.90 / 20.7$ & $0.00 / 0.44 / 13.5$ \\
\hline HH, FCOVER & $0.01 / 5.87 / 20.6$ & $0.00 / 0.47 / 15.4$ \\
\hline HH, NDVI, FAPAR, FCOVER & $-0.04 / 5.76 / 19.8$ & $0.00 / 0.37 / 11.7$ \\
\hline
\end{tabular}


TABLE 3

STATISTICS ON THE ESTIMATION OF SOIL MOISTURE (MV IN VOL.\%), LAI, BIOMASS (BIO IN KG/M²), VEGETATION WATER CONTENT (VWC IN $\left.\mathrm{KG} / \mathrm{M}^{2}\right)$, VEGETATION HEIGHT $($ VEH IN CM). BIAS = ESTIMATED - IN SITU, SE = SHANNON ENTROPY, PSS = PAULI SURFACE SCATTERING, PDB = Pauli Double-Bounce.

\begin{tabular}{|c|c|c|}
\hline Configuration & $\mathrm{HH}, \mathrm{VV}, \mathrm{SE}, \mathrm{PSS}, \mathrm{PDB}, \mathrm{NDVI}$ & $\begin{array}{c}\mathrm{HH}, \mathrm{VV}, \mathrm{SE}, \mathrm{PSS}, \mathrm{PDB}, \mathrm{NDVI} \\
\text { FAPAR, FCOVER }\end{array}$ \\
\hline $\begin{array}{l}\text { Bias (vol.\%)/ RMSE (vol.\%)/ARE (\%) } \\
\text { on mv }\end{array}$ & $0.10 / 5.78 / 20.6$ & $0.00 / 5.67 / 19.9$ \\
\hline $\begin{array}{c}\text { Bias }\left(\mathbf{m}^{2} / \mathbf{m}^{2}\right) / \mathbf{R M S E}\left(\mathbf{m}^{2} / \mathbf{m}^{2}\right) / \text { ARE }(\%) \\
\text { on LAI }\end{array}$ & $-0.01 / 0.59 / 18.2$ & $0.01 / 0.37 / 12.0$ \\
\hline $\begin{array}{l}\text { Bias }\left(\mathbf{k g} / \mathbf{m}^{2}\right) / \mathrm{RMSE}\left(\mathrm{kg} / \mathrm{m}^{2}\right) / \mathrm{ARE}(\%) \\
\text { on BIO }\end{array}$ & $0.03 / 0.47 / 35.2$ & $0.03 / 0.44 / 34.2$ \\
\hline $\begin{array}{c}\text { Bias }\left(\mathbf{k g} / \mathbf{m}^{2}\right) / \text { RMSE }\left(\mathbf{k g} / \mathbf{m}^{2}\right) / \text { ARE }(\%) \\
\text { on VWC }\end{array}$ & $0.02 / 0.37 / 43.3$ & $0.02 / 0.36 / 45.5$ \\
\hline $\begin{array}{l}\text { Bias }(\mathbf{c m}) / \text { RMSE }(\mathbf{c m}) / \text { ARE (\%) } \\
\text { on VEH }\end{array}$ & $0.50 / 13.87 / 38.8$ & $0.82 / 13.45 / 39.0$ \\
\hline
\end{tabular}




\begin{tabular}{|c|c|}
\hline & $\begin{array}{l}\text { Nicolas N. Baghdadi received the } \\
\text { Ph.D. degrees from the University of } \\
\text { Toulon, France in 1994. From } 1995 \text { to } \\
\text { 1997, he was postdoctoral research at } \\
\text { INRS ETE - Water Earth Environment } \\
\text { Research Centre, Quebec University, } \\
\text { Canada. From } 1998 \text { to } 2008 \text {, he was } \\
\text { with French geological Survey } \\
\text { (BRGM), Orléans, France. Since 2008, } \\
\text { he is a Senior Scientist with the } \\
\text { National Research Institute of Science } \\
\text { and Technology for Environment and } \\
\text { Agriculture (IRSTEA), Montpellier, } \\
\text { France. } \\
\text { His research activities involve in the } \\
\text { areas of microwave remote sensing, } \\
\text { image processing, and analysis for } \\
\text { satellite and airborne remote sensing } \\
\text { data. His main field of interest is the } \\
\text { analysis of SAR data and the retrieval } \\
\text { of soil parameters (surface roughness } \\
\text { and moisture content). }\end{array}$ \\
\hline & $\begin{array}{l}\text { Mohamad El Hajj received an engineer } \\
\text { degree in Geomatics from the Islamic } \\
\text { university of Lebanon in 2010, and a } \\
\text { professional master in land management } \\
\text { from the AgroParisTech University of } \\
\text { France in 2011. He is currently working } \\
\text { toward the Ph.D degree at the University of } \\
\text { AgroParisTech (TETIS research unit), } \\
\text { focusing on radar and optical technics for } \\
\text { water resource management in agriculture } \\
\text { area. }\end{array}$ \\
\hline & $\begin{array}{l}\text { Mehrez Zribi received the } \\
\text { engineering degree in signal } \\
\text { processing from the Ecole Nationale } \\
\text { Supérieure d'Ingénieurs en } \\
\text { Constructions Aéronautiques } \\
\text { (ENSICA), Toulouse, France, and the } \\
\text { Ph.D. degree from the University of } \\
\text { Paul Sabatier, Toulouse, France. In } \\
\text { 1995, he joined the CETP laboratory } \\
\text { (IPSL/CNRS), Vélizy, France. He is } \\
\text { employed by CNRS (Centre National } \\
\text { de Recherche Scientifique) since } 2001 . \\
\text { In October 2008, he joined CESBIO } \\
\text { laboratory. His research interests } \\
\text { include microwave remote sensing } \\
\text { applied to hydrology and microwave } \\
\text { modeling and instrumentations. }\end{array}$ \\
\hline & $\begin{array}{l}\text { Ibrahim Fayad received the B.E in } \\
\text { computer and communications engineering } \\
\text { from the Islamic university of Lebanon in } \\
\text { 2011, and the Ph.D. degree from the } \\
\text { University of Montpellier, France in } \\
\text { 2015. His research activities focuses on } \\
\text { LiDAR techniques and data fusion in } \\
\text { forestry applications. }\end{array}$ \\
\hline
\end{tabular}

